2021-06

The Impact of OceanWave Coupling on the Upper Ocean Circulation During

\title{
Storm Events
}

\section{Bruciaferri, D}

http://hdl.handle.net/10026.1/17950

\subsection{9/2021jc017343 \\ Journal of Geophysical Research: Oceans \\ American Geophysical Union}

All content in PEARL is protected by copyright law. Author manuscripts are made available in accordance with publisher policies. Please cite only the published version using the details provided on the item record or document. In the absence of an open licence (e.g. Creative Commons), permissions for further reuse of content should be sought from the publisher or author. 


\section{RESEARCH ARTICLE \\ 10.1029/2021JC017343 \\ Key Points: \\ - Impact of ocean-wave coupling on Lagrangian trajectories during storm events is assessed and analyzed \\ - Coupled system simulates more accurate surface dynamics than uncoupled models with larger improvement on the shelf \\ - The Coriolis-Stokes force is the dominant wave interaction for both surface and $15 \mathrm{~m}$ drogued drifters}

Correspondence to:

D. Bruciaferri,

diego.bruciaferri@metoffice.gov.uk

Citation:

Bruciaferri, D., Tonani, M., Lewis, H. W., Siddorn, J. R., Saulter, A., Castillo Sanchez, J. M., et al. (2021). The impact of ocean-wave coupling on the upper ocean circulation during storm events. Journal of Geophysical Research: Oceans, 126, e2021JC017343. https:// doi.org/10.1029/2021JC017343

Received 10 MAR 2021 Accepted 29 MAY 2021 (c) 2021. Crown copyright. This article is published with the permission of the Controller of HMSO and the Queen's Printer for Scotland.

This is an open access article under the terms of the Creative Commons Attribution-NonCommercial License, which permits use, distribution and reproduction in any medium, provided the original work is properly cited and is not used for commercial purposes.

\section{The Impact of Ocean-Wave Coupling on the Upper Ocean Circulation During Storm Events}

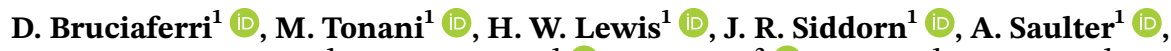 \\ J. M. Castillo Sanchez ${ }^{1}$, N. G. Valiente ${ }^{1}$ D, D. Conley ${ }^{2}$ D, P. Sykes ${ }^{1}$, I. Ascione ${ }^{1}$, and N. McConnell ${ }^{1}$ \\ ${ }^{1}$ Met Office, Exeter, UK, ${ }^{2}$ Faculty of Science and Engineering, University of Plymouth, Plymouth, UK
}

\begin{abstract}
Many human activities rely on accurate knowledge of the sea surface dynamics. This is especially true during storm events, when wave-current interactions might represent a leading order process of the upper ocean. In this study, we assess and analyze the impact of including three wavedependent processes in the ocean momentum equation of the Met Office North West European Shelf ocean-wave forecasting system on the accuracy of the simulated surface circulation. The analysis is conducted using ocean currents and Stokes drift data produced by different implementations of the coupled forecasting systems to simulate the trajectories of surface (iSphere) and $15 \mathrm{~m}$ drogued (SVP) drifters affected by four storms selected from winter 2016. Ocean and wave simulations differ only in the degree of coupling and the skills of the Lagrangian simulations are evaluated by comparing model results against the observed drifter tracks. Results show that, during extreme events, ocean-wave coupling improves the accuracy of the surface dynamics by $4 \%$. Improvements are larger for ocean currents on the shelf $(8 \%)$ than in the open ocean (4\%): this is thought to be due to the synergy between strong tidal currents and more mature decaying waves. We found that the Coriolis-Stokes forcing is the dominant wave-current interaction for both type of drifters; for iSpheres the secondary wave effect is the wavedependent sea surface roughness while for SVPs the wave-modulated water-side stress is more important. Our results indicate that coupled ocean-wave systems may play a key role for improving the accuracy of particle transport simulations.
\end{abstract}

Plain Language Summary Precise data on ocean surface velocities are of fundamental importance for several human activities, such as search and rescue or oil spill and plastic dispersal monitoring and control operations. Measurements of the surface dynamics are usually scarce both in time and space and typically data from numerical models are used instead. Traditionally, ocean and wave-induced currents are computed by ocean and wave models which are run independently from each other. In this study, we investigate the impact on the predicted surface circulation of using a coupled system where the ocean model receives the feedbacks of three wave-related processes. Since during storm conditions large waves can exert a strong control on the upper ocean circulation, we focus our study on extreme events. Our results show that the coupled system generally improves the accuracy of the predicted surface circulation by $4 \%$, with improvements larger on the shelf than in the open ocean.

\section{Introduction}

Accurate knowledge of the ocean surface dynamics is of fundamental importance for many human activities, such as shipping, commercial fishing, recreational boating, tidal energy quantification and marine ecosystems management (e.g., Dohan \& Maximenko, 2010). One key application of ocean surface currents data is the ability to predict the motion of objects floating on the sea surface. This is the case, for example, of search and rescue and pollutant dispersal operations (e.g., Breivik \& Allen, 2008; Breivik et al., 2013; De Dominicis et al., 2016; C. E. Jones et al., 2016) or monitoring activities of floating marine debris fate and accumulation (e.g., Liubartseva et al., 2018). However, the precision of such simulations drastically depends on the accuracy of the wind and ocean surface currents data used to force the Lagrangian transport model. For example, De Dominicis et al. (2016) showed that, after $24 \mathrm{~h}$, the distance between observed and predicted drifter locations can range from $2-5 \mathrm{~km}$ up to $15-25 \mathrm{~km}$, depending on the model data used to force the particle tracking model. Similarly, Dagestad and Röhrs (2019) found that, after $48 \mathrm{~h}$, drifter trajectories simulated using surface currents detected from satellite or computed by a number of ocean models with different resolution may present a separation distance from the observed tracks of about $20-25 \mathrm{~km}$. 
The need for more precise and detailed predictions of the ocean surface currents initiated intense development of new and more accurate observation technology and numerical modeling systems. For example, worldwide operational High Frequency (HF) coastal radar networks that provide real-time 2D surface current vector maps to a variety of end users represent nowadays a standard observational application (e.g., Abascal et al., 2012). Also, the Sea surface KInematics Multiscale monitoring satellite mission designed to provide direct global-coverage measurements of the total surface current velocity was proposed as a candidate for the European Space Agency Earth Explorer 9 competition (Marié et al., 2020). However, the spatial and temporal coverage of observational data is generally not sufficient to fulfil the practical needs of operational activities and typically, surface currents data from prognostic numerical models of the ocean, atmosphere and sea state are used instead (Breivik et al., 2013; Cucco et al., 2012; Zodiatis et al., 2016). It is crucial therefore to continuously assess and improve the accuracy of the surface circulation fields produced by our numerical models. One approach toward improving model data quality is to implement more integrated frameworks where numerical models of different sub-components of the Earth system (i.e., atmosphere, ocean, waves, land, ice) are combined with various degrees of coupling (e.g., Clementi et al., 2017; Lewis, Castillo Sanchez, Arnold, et al., 2019; Lewis, Castillo Sanchez, Siddorn, et al., 2019; Staneva, Wahle, Günther, \& Stanev, 2016).

One method to evaluate the precision of the upper ocean circulation reproduced by a numerical model is to use the surface velocities data to force a Lagrangian particle transport model and compare the simulated trajectories against those of satellite-tracked drifters. For example, Barron et al. (2007) applied this method to assess the impact of assimilating sea surface height on the surface circulation predicted by a U.S. Navy global ocean model. Similarly, De Dominicis et al. (2014) compared observed and numerical drifter tracks to evaluate the quality of surface velocities data produced by a number of different relocatable ocean models. The same methodology has also been used to investigate the physical mechanisms driving the surface transport (e.g., Carniel et al., 2009; Röhrs et al., 2012; Staneva et al., 2021).

Sea-state dependent processes strongly affect the upper ocean dynamics. For example, ocean waves directly contribute to the surface circulation inducing a mean Stokes drift in the direction of wave propagation (Stokes, 1847). Such a wave-induced drift can range from $0.6 \%$ to $1.3 \%$ of the wind speed and can be of similar magnitude as the direct wind-induced currents (Ardhuin et al., 2009), significantly affecting the transport of floating objects (e.g., Clarke \& Van Gorder, 2018; Staneva et al., 2021; Tamtare et al., 2021). In addition, when the Stokes drift interacts with the planetary vorticity, a new forcing appears in the ocean momentum equation which significantly affects the upper ocean Ekman spiral and therefore the direction of the surface Lagrangian transport (Polton et al., 2005; Röhrs et al., 2012). Ocean waves also modulates the transfer of momentum from the atmosphere to the ocean (Komen et al., 1994), modifying the upper ocean circulation (e.g., Wu et al., 2019) and hence Lagrangian trajectories (e.g., Tang et al., 2007). In addition, surface gravity waves directly control the vertical structure of upper ocean currents. For example, the sea surface roughness, which is the length scale controlling the turbulent mixing at the sea surface (e.g., Gemmrich \& Farmer, 1999), is sea-state dependent (e.g., Rascle et al., 2008). Also, when wind-waves break, the turbulent dissipation in the uppermost part of the oceanic boundary layer is enhanced (e.g., Gerbi et al., 2009). In shallow waters, wind-waves can interact with the bottom topography, enhancing the near-bed turbulence and hence modifying the bottom drag coefficient and the currents shear (e.g., Davies \& Lawrence, 1995). Whilst the importance of including the Stokes drift on the total upper ocean transport has been investigated extensively (e.g., Callies et al., 2017; De Dominicis et al., 2016; Tamtare et al., 2021), the impact of wave-current interactions on the surface circulation has received less attention (e.g., Carniel et al., 2009; Röhrs et al., 2012), especially for cases when more wave-related processes are considered at the same time (Staneva et al., 2021).

During sea storm events, large waves can have a strong control on the surface ocean dynamics, making wave-current interactions a leading order process of the uppermost part of the ocean (e.g., Carniel et al., 2009; Staneva, Wahle, Koch, et al., 2016; Staneva et al., 2017; Wu et al., 2019). The North West European shelf (NWS) is a shallow tidal flat with significant coastal populations and infrastructures which can be affected by extremely severe sea storms (e.g., Masselink et al., 2016; Wei et al., 2019), increasing the demand for accurate predictions of the surface ocean dynamics. In 2020 for example, ocean currents represented $\approx 50 \%$ of the NWS total downloaded physical ocean forecast products at $1.5 \mathrm{~km}$, as reported by the 
Copernicus Marine Environment Monitoring Service (CMEMS; see, e.g., Le Traon et al., 2019 for a summary of the service) service desk. CMEMS ocean and wave analysis and forecast data at $1.5 \mathrm{~km}$ of resolution for the NWS area are produced by the Met Office ocean and wave forecasting system (Saulter et al., 2017; Tonani et al., 2019). In order to improve the accuracy of these products, since December 15, 2020 the NWS operational system uses a coupled ocean-wave modeling framework. In this system, the momentum budget equation solved by the ocean model is modified to include three wave feedbacks, namely the Coriolis-Stokes force (CSF), a wave modified momentum flux and a sea-state dependent sea surface roughness as described in Lewis, Castillo Sanchez, Arnold, et al. (2019); Lewis, Castillo Sanchez, Siddorn, et al. (2019).

This study has three objectives:

- assess and quantify the accuracy of the surface dynamics simulated by the NWS ocean-wave coupled forecasting system in the presence of severe sea-states;

- analyze the physical mechanisms underpinning the impact of the three wave-current interactions included in the NWS ocean-wave coupled system on the upper ocean circulation during storm events; and

- identify possible future models and coupling developments which may further improve the upper ocean physics represented by the NWS coupled system.

In order to address these questions, ocean currents and Stokes' drift simulations produced by five versions of the NWS forecasting system differing only in the degree of ocean-wave coupling are compared. The assessment is conducted using surface velocity data from the five experiments to simulate the Lagrangian trajectories of a number of drifters affected by four Atlantic storms that crossed the NWS during winter 2016. The skills of the Lagrangian simulations are evaluated comparing model results against the observed drifters' tracks.

The study is organized as follows. Section 2.1 details the NWS ocean-wave forecasting system (the model components as well as the coupling strategy). The Lagrangian simulations are described in Section 2.2.1 and the experimental design is presented in Section 2.2.2. Drifter observations used for the assessment are presented in Section 2.3. In Section 3 we use an idealized model to conduct some first order analysis of the impact of the three wave feedbacks included in the coupling which will help also in interpreting the 3D model results. In Section 4 we present and analyze our results. In Section 5 the physical mechanism underlying the impact of ocean-wave coupling during extreme events are discussed. Finally, in Section 6 we summarize our main conclusions.

\section{Methods and Data}

\subsection{The NWS Ocean-Wave Forecasting System}

Ocean and wave data to force the Lagrangian simulations were produced using the Met Office NWS ocean and wave forecasting system, a component of CMEMS.

\subsubsection{The Ocean Component}

The ocean component of the prediction system is a Forecasting Ocean Assimilation Model (FOAM) of the NWS including an ocean model and a variational data assimilation scheme. Here, only the aspects of the FOAM system which are relevant to our study are given, while a detailed description can be found in Tonani et al. (2019).

The ocean model is AMM15-ocean, the eddy resolving configuration of the Atlantic Margin Model described in Graham, O'Dea, et al. (2018) and based on version 3.6 of the Nucleus for European Modeling of the Ocean (NEMO) numerical code (Madec \& NEMO-team, 2016). AMM15-ocean uses a horizontal curvilinear grid with a uniform grid spacing of $\approx 1.5 \mathrm{~km}$ with a $z^{*}-s$ vertical grid with 51 levels (Siddorn \& Furner, 2013). Tidal dynamics are represented employing a nonlinear free surface along with a time-splitting scheme that separates the fast external mode from the slow baroclinic modes. Turbulent vertical viscosity and diffusivity are computed using the Generic Length Scale (GLS) scheme (Umlauf \& Burchard, 2003; see also Section 2.1.3 for more details). Air-sea fluxes are computed using the CORE bulk formulae (Large \& Yeager, 2009) using 3-hourly atmospheric fields with a resolution of $0.125^{\circ} \times 0.125^{\circ}$ provided by the 
European Centre for Medium-Range Weather Forecasts (ECMWF) operational Integrated Forecasting System (IFS).

The data assimilation component of the FOAM-AMM15 system is NEMOVAR, an incremental first guess at an appropriate time 3DVAR scheme. The Met Office implementation of NEMOVAR includes bias correction scheme for both sea surface temperature (SST) and altimeter data (see King et al., 2018; Waters et al., 2015 for the details). FOAM-AMM15 implements NEMOVAR version 4 and uses an assimilation window of $24 \mathrm{~h}$, assimilating in-situ and satellite-swath SST observations, altimeter measurements of sea level anomaly (in regions with depth $>700 \mathrm{~m}$ ) and profile observations of temperature and salinity of the water column from different sources (see King et al., 2018 for the details). In this study only hourly analysis ocean data are used.

Tonani et al. (2019) showed that FOAM-AMM15 correctly reproduces the main hydrographic and dynamical features of the NWS, both in coastal and off-shelf areas. The high resolution of this system allows to resolve oceanographic structures at meanders and eddies scales, improving the model skills in reproducing important circulation patterns such as the European slope currents or the across shelf transport (Graham, Rosser, et al., 2018). The circulation in the shallow, tidally dominated area has a good agreement with observations.

\subsubsection{The Wave Component}

The wave component of the NWS prediction system is AMM15-wave, a regional implementation of the WAVEWATCH III spectral wave model version 4.18 (Tolman, 2014) as detailed in Saulter et al. (2017). The domain of AMM15-wave covers the same area of AMM15-ocean model but uses a Spherical Multiple Cell discretization scheme ( $\mathrm{Li}, 2012)$ configured to have a variable horizontal resolution ranging from $3 \mathrm{~km}$ across much of the domain down to $1.5 \mathrm{~km}$ near the coast or where the average depth is shallower than $40 \mathrm{~m}$. The wave model is forced with the same 3-hourly ECMWF wind fields that are used to force AMM15ocean. In addition, the uncoupled wave model is forced with hourly externally provided AMM15-ocean surface currents (Palmer \& Saulter, 2016) while in the coupled implementation surface currents are exchanged via the ocean-wave coupler (Lewis, Castillo Sanchez, Arnold, et al., 2019; Lewis, Castillo Sanchez, Siddorn, et al., 2019). Wave growth and dissipation terms are parameterized using the ST4 physics following Ardhuin et al. (2010) while nonlinear wave-wave interactions use the Discrete Interaction Approximation (DIA) package according to Hasselmann et al. (1985). In this study we use hourly analysis wave data.

\subsubsection{The Coupled System}

Ocean-wave coupling in FOAM-AMM15 is implemented as described by Lewis, Castillo Sanchez, Arnold, et al. (2019); Lewis, Castillo Sanchez, Siddorn, et al. (2019), considering only wave feedbacks acting on the ocean momentum budget equation.

When wave-current interactions are not taken into account, AMM15-ocean solves the incompressible, hydrostatic and Boussinesq approximated ocean momentum budget equation

$$
\left\{\begin{array}{l}
\frac{\partial \boldsymbol{u}_{h}}{\partial t}+[\boldsymbol{u} \cdot \nabla \boldsymbol{u}]_{h}+f \hat{\boldsymbol{z}} \times \boldsymbol{u}=-\nabla \frac{p}{\rho_{w}}+b \hat{\boldsymbol{z}}+\boldsymbol{D}_{h}+\frac{\partial}{\partial z} A_{v}^{o} \frac{\partial \boldsymbol{u}_{h}}{\partial z} \\
\left.A_{v}^{o} \frac{\partial \boldsymbol{u}_{h}}{\partial z}\right|_{z=\eta}=\frac{\tau_{a t m}}{\rho_{w}}
\end{array}\right.
$$

Here the subscript $h$ identifies a $2 \mathrm{D}$ vector with components in the zonal $(\hat{\boldsymbol{x}})$ and meridional $(\hat{\boldsymbol{y}})$ directions, $\mathbf{u}=\boldsymbol{u}_{h}+w \hat{\boldsymbol{z}}=(u, v, w)$ represents the Eulerian velocity vector field of slowly evolving ocean currents (with $\hat{z}$ the local upward vertical unit vector), $f$ is the Coriolis parameter, $t$ is time, $p$ is pressure, $b=-g \rho / \rho_{w}$ is the buoyancy with $\rho$ the ocean density, $\rho_{w}$ a reference ocean density and $g$ gravity, $z$ is the height referenced to the geoid, $\eta$ is the ocean free surface, $\boldsymbol{D}_{h}$ represents the parameterization of sub-grid physics in the lateral direction and $\tau_{a t m}$ is the stress exerted by the atmospheric wind on the ocean surface.

The vertical eddy viscosity $A_{v}^{o}$ is computed by AMM15-ocean using the two-equation GLS turbulent closure model with the following surface boundary conditions (see Reffray et al., 2015 for the details about the NEMO implementation):

- surface enhanced mixing due to wave-breaking according to Craig and Banner (1994) scheme 


$$
\frac{A_{v}^{o}}{\sigma_{k}} \frac{\partial k}{\partial z} I_{z=\eta}=C_{w} u_{*_{w}}^{3},
$$

where $k$ is the turbulent kinetic energy, $\sigma_{k}$ is the constant Schmidt number for $\mathrm{k}, C_{w}$ is the Craig and Banner coefficient equal to 100 and $u_{*_{w}}=\left(\left|\boldsymbol{\tau}_{\boldsymbol{a t m}}\right| \rho_{w}^{-1}\right)^{1 / 2}$ is the water-side friction velocity;

- sea surface roughness $z_{0}$ as a function of the significant wave height $H_{s}$ as proposed by Rascle et al. (2008):

$$
z_{0}=\alpha H_{s}
$$

with $\alpha=1.3$ and

$$
\begin{gathered}
H_{s}=\frac{665}{0.85 g} u_{*_{w}}^{2} W_{\text {age }}^{\frac{3}{2}}, \\
W_{\text {age }}=30 \tanh \left(\frac{0.6}{28 u_{*_{w}}}\right),
\end{gathered}
$$

where $W_{\text {age }}$ is an estimate of the wave age as a function of the wind stress (the superscript $o$ in the vertical eddy viscosity $A_{v}^{o}$ emphasizes the fact that when ocean-wave coupling is switched off the $H_{s}$ is estimated by the ocean model).

Equation $1 \mathrm{~b}$ represents the surface boundary condition traditionally used in uncoupled ocean models, where it is assumed that at the air-sea interface the air-side momentum flux (i.e., the wind stress $\tau_{a t m}$ ) is completely transferred into the ocean. When FOAM-AMM15 system is uncoupled, the $\tau_{a t m}$ is computed by NEMO as

$$
\boldsymbol{\tau}_{a t m}=\rho_{a} C_{D}\left|\boldsymbol{U}_{10}\right| \boldsymbol{U}_{10},
$$

where $\rho_{a}$ is the air density, $\boldsymbol{U}_{10}$ is the wind velocity at $10 \mathrm{~m}$ and $C_{D}$ is the drag coefficient computed according to Large and Yeager (2009).

When ocean-coupling is activated, the momentum budget equation solved by the ocean model of the FOAM-AMM15 forecasting system is modified as follows:

$$
\left\{\begin{array}{l}
\frac{\partial \boldsymbol{u}_{h}}{\partial t}+[\boldsymbol{u} \cdot \nabla \boldsymbol{u}]_{h}+f \hat{\boldsymbol{z}} \times\left(\boldsymbol{u}+\boldsymbol{u}_{s}\right)=-\nabla \frac{p}{\rho_{w}}+b \hat{\boldsymbol{z}}+\boldsymbol{D}_{h}+\frac{\partial}{\partial z} A_{v}^{w} \frac{\partial \boldsymbol{u}_{h}}{\partial z}, \\
A_{v}^{w} \frac{\partial \boldsymbol{u}_{h}}{\partial z} I_{z=\eta}=\frac{\tau_{o c n}}{\rho_{w}} .
\end{array}\right.
$$

Equation 7 is a wave-averaged momentum balance equation including three wave effects acting on the mean flow (see Lewis, Castillo Sanchez, Arnold, et al., 2019; Lewis, Castillo Sanchez, Siddorn, et al., 2019 for the details):

\section{Coriolis-Stokes forcing}

Surface waves induce a mean Lagrangian drift $\boldsymbol{u}_{s}$ in their direction of propagation known as Stokes drift (e.g., Phillips, 1977; Stokes, 1847). When the wave-induced drift interacts with the planetary vorticity, an additional force named CSF appears in the wave-averaged Eulerian momentum equation (Hasselmann, 1970)

$$
C S F \equiv f \hat{z} \times \boldsymbol{u}_{s}
$$

In the FOAM-AMM15 coupled system, the Stokes' Drift at the surface $\boldsymbol{u}_{s}^{0}=\boldsymbol{u}_{s}(t, x, y, 0)$ is computed by AMM15-wave model and exchanged with AMM15-ocean model together with the $H_{s}$ and the mean wave period $T_{01}$. Then, the 3D Stokes drift $\boldsymbol{u}_{s}$ is estimated by AMM15-ocean according to Breivik et al. (2016) 


$$
\boldsymbol{u}_{s}=\boldsymbol{u}_{s}^{0}\left[e^{2 k_{p} z}-\beta \sqrt{-2 k_{p} \pi z} \operatorname{erfc}\left(\sqrt{2 k_{p} z}\right)\right]
$$

where erfc is the complementary error function, $\beta=1$ and $k_{p}=\frac{8 u_{s}^{0} T_{01}}{\gamma \pi H_{s}^{2}}$ with $\gamma=5.97$.

2. Sea-state dependent water-side momentum flux

The blowing of the wind on the sea surface generates both ocean waves and currents (e.g., Csanady \& Gibson, 2001). As a result, sheared ocean currents are directly forced by the total wind stress $\tau_{\text {atm }}$ only in the case of fully developed wind-waves (Pierson \& Moskowitz, 1964). Most of the time, the wavefield is far from being in equilibrium with the local wind, and waves are either growing, with a net influx of momentum into the wavefield, or decaying, with intensified wave-breaking and a net outflux of momentum from waves into the ocean (e.g., Komen et al., 1994). Thus, when surface waves are considered the water-side momentum flux $\tau_{\text {ocn }}$ (i.e., the stress that effectively forces the ocean at the surface) is given by (e.g., Breivik et al., 2015)

$$
\boldsymbol{\tau}_{o c n}=\boldsymbol{\tau}_{a t m}-\boldsymbol{\tau}_{a t w}+\boldsymbol{\tau}_{w o c},
$$

where $\tau_{a t w}$ is the momentum flux absorbed by the waves (aka the wave-supported stress) and $\tau_{\text {woc }}$ is the momentum flux from the wavefield to the mean flow.

In the FOAM-AMM15 coupled system $\tau_{\text {ocn }}$ is computed by AMM15-wave and directly passed to the ocean model.

3. Sea-state dependent sea surface roughness

FOAM-AMM15 estimates the sea surface roughness $z_{0}$ from the significant wave height $H_{s}$. When run in coupled mode, $H_{s}$ is computed by AMM15-wave and exchanged with AMM15-ocean that then uses Equation 3 to compute $z_{0}$ (as indicated by the superscript $w$ in the vertical eddy viscosity $A_{v}^{w}$ ).

\subsection{Numerical Experiments}

\subsubsection{Lagrangian Simulations}

Drifter trajectories were simulated using the OpenDrift Lagrangian framework [Dagestad \& Röhrs, 2019; Dagestad et al., 2018). We used a 4th order Runge-Kutta scheme and a timestep of 3,600 $s$ to integrate the following initial value problem for the drifter position $\boldsymbol{x}(t)=(x(t), y(t))$ :

$$
\left\{\begin{array}{l}
\frac{d \boldsymbol{x}(t)}{d t}=\boldsymbol{u}(\boldsymbol{x}(t), t)+\boldsymbol{u}_{s}(\boldsymbol{x}(t), t)+\boldsymbol{u}_{w}(\boldsymbol{x}(t), t)+\boldsymbol{u}^{\prime}(\boldsymbol{x}(t), t), \\
\boldsymbol{x}\left(t_{0}\right)=\boldsymbol{x}_{0}
\end{array}\right.
$$

where $\boldsymbol{x}_{0}$ is the initial drifter position at time $t_{0}$.

Two different type of drifters are simulated in this study, iSphere and Surface Velocity Program (SVP) drifters. SVP drifters are drifting buoys used since the early 1980s to measure ocean currents at a nominal depth of $15 \mathrm{~m}$. They are formed by a surface float connected to a subsurface 7-m-long holey sock drogue centered at $15 \mathrm{~m}$ depth (Lumpkin \& Pazos, 2009). Such a design allows to reduce the wind slippage to less than $0.1 \%$ in $10 \mathrm{~m} \mathrm{~s}^{-1}$ wind speed (Niller et al., 1987), so that drogued SVP drifters are mainly transported by ocean currents and the Stokes drift at $15 \mathrm{~m}$ depth (Rio, 2012). Conversely, iSphere drifters are half submerged spherical drifting buoy where the drifting velocity results from the combination of surface ocean and wave-induced currents and direct wind leeway (De Dominicis et al., 2016; Röhrs et al., 2012).

In the case of iSphere drifters, $\boldsymbol{u}(\boldsymbol{x}(t), t)$ and $\boldsymbol{u}_{s}(\boldsymbol{x}(t), t)$ represent turbulent Eulerian ocean currents and the Stokes drift at $0.5 m$ (i.e., the depth of the upper ocean model level) respectively, while $\boldsymbol{u}_{w}(\boldsymbol{x}(t), t)$ is the wind drag velocity parameterized as

$$
\boldsymbol{u}_{w}(\boldsymbol{x}(t), t)=\gamma \boldsymbol{U}_{10}(\boldsymbol{x}(t), t)
$$


where $\boldsymbol{U}_{10}(\boldsymbol{x}(t), t)$ is the wind velocity at $10 \mathrm{~m}$ and $\gamma=0.01$ in agreement with De Dominicis et al. (2016); Röhrs et al. (2012).

When simulating SVP drifters $\boldsymbol{u}(\boldsymbol{x}(t), t)$ and $\boldsymbol{u}_{s}(\boldsymbol{x}(t), t)$ represent Eulerian ocean currents and the Stokes drift at $15 m$ while $\boldsymbol{u}_{w}=0$. The Stokes drift at 0.5 and $15 m$ was estimated from the Stokes drift at the surface applying Breivik et al. (2016) parameterization (see Equation 9).

The term $\boldsymbol{u}^{\prime}(\boldsymbol{x}(t), t)=\alpha R$ with $R \in[-1,1]$ represents random fluctuations in the velocity field to simulate sub-grid turbulent diffusion. We use $\alpha=0.04 \mathrm{~m} \mathrm{~s}^{-1}$ which corresponds to a horizontal eddy diffusivity $K_{h}$ of $\approx 1 \mathrm{~m}^{2} \mathrm{~s}^{-1}$ when modeling sub-grid turbulence as a random walk diffusive process (e.g., De Dominicis et al., 2013), in agreement with S. Jones et al. (2020).

Quantitative assessment of the accuracy of the simulated drifter trajectories has been carried out using the Liu and Weisbe (2011) skill score (ss). This metric compares modeled and observed drifter trajectories along their path evaluating the separation of the two trajectories normalized by their total length:

$$
s=\frac{\sum_{i=0}^{N} d_{i}\left(\boldsymbol{x}_{s}\left(t_{i}\right), \boldsymbol{x}_{o}\left(t_{i}\right)\right)}{\sum_{i=0}^{N} l_{o i}\left(\boldsymbol{x}_{o}\left(t_{0}\right), \boldsymbol{x}_{o}\left(t_{i}\right)\right)},
$$

where $N$ is the total number of observed drifter positions in a given trajectory, $t_{i}$ is the time at which the $i$ th drifter position has been recorded, $t_{0}$ is the time at which the drifter has been deployed, $d_{i}$ are distances between simulated $\boldsymbol{x}_{s}\left(t_{i}\right)$ and observed $\boldsymbol{x}_{o}\left(t_{i}\right)$ drifter positions at time $t_{i}$ and $l_{o i}$ is the length of the observed trajectory at time $t_{i}$.

The skill score ss is then defined as

$$
s s= \begin{cases}1-s & , \text { if } s \leq 1, \\ 0 & , \text { if } s>1,\end{cases}
$$

so that $s s=1$ indicates perfectly aligned observed and modeled trajectories while $s s=0$ identifies model simulations with no skill. Besides taking account for the separation at the end of two trajectories, the Liu and Weisberg (2011) skill score also acknowledges some skill for trajectories that stay together during the beginning of their path, but separate toward the end.

For each drifter simulation, 100 particles were released at the same initial location and time: the skill score of each numerical track was computed considering the path of the barycentre of the spatial distribution of particles while the standard deviation of the ss computed for each of the 100 particles was used as a measure of the associated uncertainty. All the simulations showed a standard deviation $<0.02$, indicating that metrics computed for the barycentre were quite representative of the local ocean dynamics. Sensitivity tests using 1,000 or 10,000 particles showed no effect on the numerical solution. Results are presented in terms of average skill scores $\overline{s s}$ and standard deviation SD, similarly to the studies of Amemou et al. (2020); Staneva et al. (2021); Tamtare et al. (2021).

\subsubsection{Experimental Design}

Four Atlantic wind-storms affecting the NWS during winter 2016 are considered in this study. They were named by the Met Office and Met Éireann as Gertrude, Henry, Imogen and Jake. A summary of meteorological and wave conditions for each storm is shown in Figure 1, and further details are provided in Table 1.

Lagrangian experiments were forced using ocean currents and Stokes drift data from five different FOAMAMM15 ocean-wave simulations as listed in Table 2.

The control trial (CTR) used the ocean and wave models in uncoupled mode (Equation 1) while the fully coupled experiment (CPL) used all the three wave feedbacks switched on (Equation 7). Both simulations were extensively validated and analyzed by Lewis, Castillo Sanchez, Siddorn, et al. (2019) (in their work the CTR and CPL trials were named DA and CPL_DA, respectively). 

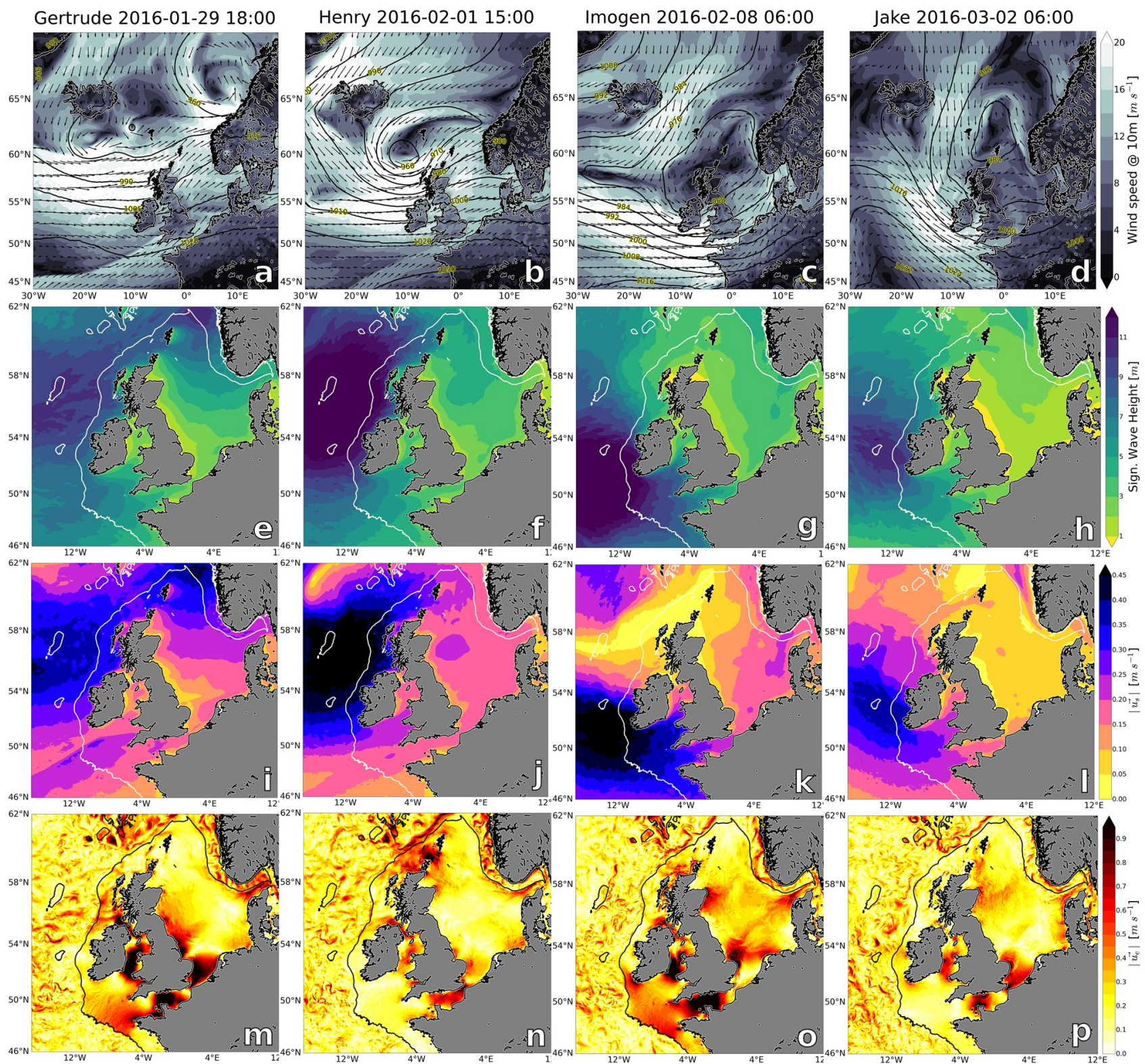

Figure 1. Snapshots of 10-m wind speed and direction and mean sea level pressure simulated by European Centre for Medium-Range Weather Forecasts (ECMWF) global-scale atmosphere forecasts, used as meteorological forcing of the North West European Shelf (NWS) ocean-wave system (upper row) and significant wave height (second row), Stokes drift speed (third row) and ocean currents speed (bottom row) simulated by the NWS ocean-wave forecasting system for storms Gertrude (leftmost column), Henry (second column), Imogen (third column) and Jake (rightmost column). Snapshots correspond to the $H_{s}$ peak of each storm.

Three more ocean-wave simulations were run specifically for this work to investigate the relative impact of the three wave effects considered in FOAM-AMM15 coupled system. All the three experiments used ocean and wave restarts from the CTR trial and covered the period from January 23 to February 11, 2016. The CSF trial used the coupled system with only the Coriolis-Stokes forcing activated (i.e., combining Equation 1 and Equation 8), while the Tau ocean (TOC) simulation switched on only the wave-dependent water-side momentum flux (i.e., Equation 1 replacing $\tau_{a t m}$ with $\tau_{o c n}$ and using Equation 10). Finally, the wave sea surface roughness (WSR) trial modified the stand-alone ocean momentum budget equation activating only the sea-state dependent sea surface roughness (i.e., using Equation 1 and Equation 3 with $H_{s}$ computed by the wave model). 
Table 1

Summary of Meteorological and Wave Conditions for the Four Storms Considered in This Study

\begin{tabular}{|c|c|c|c|c|c|c|}
\hline $\begin{array}{l}\text { Storm } \\
\text { name }\end{array}$ & $\begin{array}{l}\text { Days when storm } \\
\text { crossed NWS }\end{array}$ & Description of the impacts & $\begin{array}{l}\text { Lowest } \\
\text { recorded } \\
\text { atm. pres. } \\
{[h P a]}\end{array}$ & $\begin{array}{l}\text { Max. } \\
\text { wind } \\
\text { gust } \\
{[m} \\
\left.s^{-1}\right]\end{array}$ & $\begin{array}{l}\text { Highest } \\
\text { signif. } \\
\text { wave } \\
\text { height } \\
{[\mathrm{m}]}\end{array}$ & References \\
\hline Gertrude & January 29-30, 2016 & $\begin{array}{l}\text { Strong winds across Scotland and northern England; 'red' (risk to life, } \\
\text { widespread disruption) UK national severe weather warning for } \\
\text { wind impacts issued by the Met Office for Shetland Islands }\end{array}$ & 948 & $\approx 45$ & 11 & $\begin{array}{l}\text { Magnusson and } \\
\text { Bidlot (2016); } \\
\text { Met } \\
\text { Office (2016a); } \\
\text { see also } \\
\text { Figures 1a-1e }\end{array}$ \\
\hline Henry & $\begin{array}{l}\text { February } 01-02, \\
\quad 2016\end{array}$ & $\begin{array}{l}\text { Heavy rain and very strong wind across Scotland, northern England } \\
\text { and northern Wales; strongest gusts recorded in the Outer Hebrides } \\
\text { and larger waves affected the northern part of the NWS. }\end{array}$ & 944 & $\approx 40$ & 12 & $\begin{array}{l}\text { Met } \\
\text { Office }(2016 \mathrm{~b}) \\
\text { see also } \\
\text { Figures } 1 \mathrm{~b}-1 \mathrm{f}\end{array}$ \\
\hline Imogen & $\begin{array}{l}\text { February } 07-08 \\
\quad 2016\end{array}$ & $\begin{array}{l}\text { Affected the south-west of England and the south of Wales with strong } \\
\text { winds and large waves. }\end{array}$ & 962 & $\approx 35$ & $10-11$ & $\begin{array}{l}\text { Met } \\
\text { Office }(2016 c) \text {; } \\
\text { see also } \\
\text { Figures } 1 \mathrm{i}-1 \mathrm{j}\end{array}$ \\
\hline Jake & March 01-04, 2016 & $\begin{array}{l}\text { Relatively moderate cyclone that affected large part of Ireland, Wales } \\
\text { and south-west England }\end{array}$ & 988.9 & $\approx 37$ & $9-10$ & $\begin{array}{l}\text { Met } \\
\text { Office }(2016 \mathrm{c}) \\
\text { see also } \\
\text { Figures } 1 \mathrm{~m}-1 \mathrm{n}\end{array}$ \\
\hline
\end{tabular}

Abbreviation: NWS, North West European Shelf.

\subsection{Ocean Drifters Observations}

Drifter observations used to assess the skills of the Lagrangian simulations were retrieved from the CMEMS NWS in-situ product (Wehde et al., 2021). This data set includes observed trajectories from (i) SVP drifters equipped with a 15-m centered drogue and ii) SVP drifters which have lost their drogue. When SVP drifters lose their drogue, they become more susceptible to the wind generated slip, which increases to $\approx 1 \%-3 \%$ of the wind speed (Pazan \& Niiler, 2001; Rio, 2012). Therefore, undrogued SVP effectively behave as iSphere drifters.

The CMEMS data set is processed with the algorithm defined in Appendix A to identify the drifters trajectories which were affected by the four storms considered in this study. After processing, a total of 49 drifter trajectories are identified (see Figure 2): 18 tracks were recorded by drogued SVP drifters (hereafter SVP) while 31 belonged to undrogued SVP drifters (hereafter iSphere since they are effectively as surface iSphere drifters). In addition, 12 tracks were observed on the shelf and shelf-break (areas with depth $\leq 200 \mathrm{~m}$ ) while

Table 2

Characteristics of the Five Ocean-Wave Model Trial Datasets Used to Force the Lagrangian Simulations (See the Text for the Details)

\begin{tabular}{|c|c|c|c|c|c|}
\hline Trial Name & $C S F$ & Water-side mom. flux & $H_{s}$ for $z_{0}$ & Simulation period & Comments \\
\hline CTR & no & $\tau_{\text {atm }}($ Equation 16) & estimated(Equation 4) & 01-01-201607-03-2016 & $\begin{array}{l}\text { Lewis, Castillo Sanchez, } \\
\text { Siddorn, et al. (2019), DA } \\
\text { experiment }\end{array}$ \\
\hline CPL & yes & $\tau_{\text {ocn }}($ Equation 10$)$ & comput. by wave model & 01-01-201607-03-2016 & $\begin{array}{l}\text { Lewis, Castillo Sanchez, } \\
\text { Siddorn, et al. (2019), } \\
\text { CPL_DA experiment }\end{array}$ \\
\hline CSF & yes & $\tau_{\text {atm }}($ Equation 16) & estimated(Equation 4) & 23-01-201606-02-2016 & initial conditionfrom CTR trial \\
\hline TOC & no & $\tau_{\text {ocn }}($ Equation 10$)$ & estimated(Equation 4) & 23-01-201606-02-2016 & initial conditionfrom CTR trial \\
\hline WSR & no & $\tau_{\text {atm }}($ Equation 16$)$ & comput. by wave model & 23-01-201606-02-2016 & initial conditionfrom CTR trial \\
\hline
\end{tabular}

Abbreviations: TOC, Tau ocean; WSR, wave sea surface roughness. 


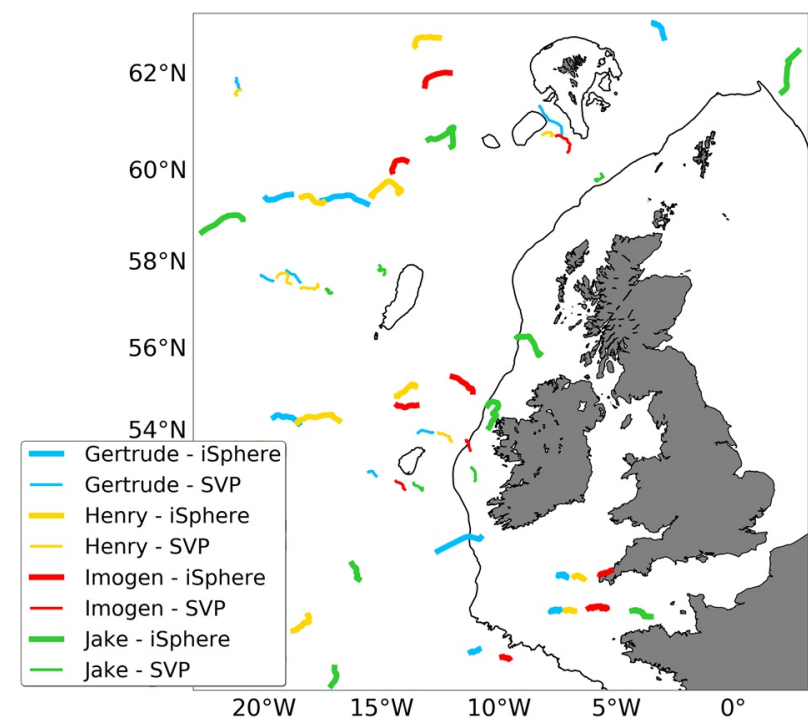

Figure 2. Drifters trajectories from the INSITU CMEMS data set which were affected by the four winter 2016 storms considered in this study. Thick lines represent the tracks of Surface Velocity Program (SVP) drifters which have lost their drogue (iSphere-like drifters) while thin lines identify SVP drifters with the drogue. The $200 \mathrm{~m}$ isobath is also shown in black. 14 tracks were recorded during storm Gertrude (light blue lines), 13 during storm Henry (yellow lines), 10 during storm Imogen (red lines) and 12 during storm Jake (green lines).
37 were in the open ocean. The algorithm described in Appendix A is designed to identify drifter tracks with maximum duration of 24-48 h. This is done in order to maximize the usability of the available data set and to reduce the separation distance between observed and simulated track to an acceptable level (e.g., Dagestad \& Röhrs, 2019; De Dominicis et al., 2014).

\section{The Importance of Coupling During Extreme Events}

In this section we use the Ekman model (Ekman, 1905) to have some sense of the relative contributions of the three wave feedbacks included in the FOAM-AMM15 coupled system to the upper ocean dynamics in the presence of severe sea-states.

The Ekman model considers the simplified case of a constant vertical viscosity and therefore may not be suitable for exploring the impact of a wave dependent sea surface roughness. However, Carniel et al. (2009) extensively investigated the effect of the sea surface roughness and wave-breaking induced turbulence on modeling drifters trajectories during a wind storm event in the Adriatic sea. They used idealized and realistic numerical experiments to show that (i) enhancing the surface roughness and/or including the injection of turbulent kinetic energy from breaking waves increases the vertical mixing of momentum reducing the shear and ultimately decreasing the upper ocean velocities; (ii) drifters' trajectories in the presence of a storm are better simulated when wave breaking processes are taken into account and the sea surface roughness is enhanced.

Therefore, we consider the Ekman problem modified to include the Coriolis-Stokes forcing (Huang, 1979; McWilliams et al., 1997; Polton et al., 2005) and a sea-state dependent water-side momentum flux:

$$
\left\{\begin{array}{l}
f \hat{\boldsymbol{z}} \times\left(\boldsymbol{u}_{h}+\boldsymbol{u}_{s}\right)=\frac{\partial}{\partial z} A_{v} \frac{\partial \boldsymbol{u}_{h}}{\partial z}, \\
\left.A_{v} \frac{\partial \boldsymbol{u}_{h}}{\partial z}\right|_{z=\eta}=\frac{\tau_{o c n}}{\rho_{w}}
\end{array}\right.
$$

where $A_{v}$ is a constant vertical viscosity coefficient and $\boldsymbol{u}_{h}$ becomes insignificant $\left(\boldsymbol{u}_{h} \rightarrow 0\right)$ at great depths $(z \rightarrow-\infty)$.

As shown by Polton et al. (2005), in this type of problem the analytical solution for the Eulerian currents results from the linear combination of three distinct terms:

$$
\boldsymbol{u}_{h}=\boldsymbol{U}_{E}+\boldsymbol{U}_{S}+\boldsymbol{U}_{E S},
$$

where $\boldsymbol{U}_{E}$ is the wind-driven part acting on the whole Ekman depth $d_{e}=\left(2 A_{v} / f\right)^{1 / 2}$ (i.e., the solution of the classical Ekman problem), $\boldsymbol{U}_{S}$ is the wave-driven Stokes component directly forced by the CSF term and decaying over the Stokes depth scale $d_{S}=(2 k)^{-1}$ and $\boldsymbol{U}_{E S}$ is the Ekman-Stokes component which decays over the total Ekman depth scale. It is important to note that (i) the Stokes component $\boldsymbol{U}_{S}$ is different from the Lagrangian Stokes drift $\boldsymbol{u}_{S}$ and (ii) the Ekman-Stokes component $\boldsymbol{U}_{E S}$ arises to balance the stress exerted by the Stokes component and hence ensuring that the total velocity satisfies the wind stress surface boundary condition (Polton et al., 2005).

Here, we assume a storm where the wind is blowing only in the zonal $\hat{\boldsymbol{x}}$ direction and monochromatic deep-water surface waves are propagating in the same direction. Monochromatic wave fields are chosen in order to approximate a dominant component in the wave spectrum (e.g., McWilliams et al., 1997; Sullivan et al., 2007). The associated Stokes drift is given by $\boldsymbol{u}_{s}=\hat{\boldsymbol{x}}(a k)^{2} c_{p} e^{2 k z}$, where $a$ is the wave amplitude, $k$ the 
wavenumber and $c_{p}$ the wave phase speed (Phillips, 1977). We choose a wind speed $U_{10}$ of $15 \mathrm{~m} \mathrm{~s}^{-1}$, a Stokes drift at the surface of $0.3 \mathrm{~m} \mathrm{~s}^{-1}, f=10^{-4} \mathrm{~s}^{-1}$ and a constant vertical eddy viscosity $A_{v}=1.16 \times 10^{-2} \mathrm{~m}^{2} \mathrm{~s}^{-1}$ (McWilliams et al., 1997; Polton et al., 2005), which corresponds to an Ekman depth scale $d_{e}$ of $\approx 15 \mathrm{~m}$. The drag coefficient $C_{D}$ is computed according to Smith and Banke (1975), yielding a wind stress magnitude $\tau_{\text {atm }}=0.43 \mathrm{~N} \mathrm{~m}^{-2}$ and a water-side friction velocity $u_{* w}$ of $0.02 \mathrm{~m} \mathrm{~s}^{-1}$.

Two representative cases are explored: one for young fast growing waves and the second for more mature decaying waves. The growing waves scenario considers wind-waves with period $T=5 \mathrm{~s}$, inverse wave age $u_{*} c_{p}^{-1}=0.08$ and ratio of the Ekman to the Stokes depth $d_{s} d_{e}^{-1}$ equal to 0.20. Wu et al. (2019) showed that during storm conditions the ratio $\tau_{o c n} \tau_{\text {atm }}^{-1}$ in the North Sea ranges between 0.8 and 1.8. Therefore, we parameterize the sea-state dependent water-side momentum flux during growing waves conditions as $\tau_{\text {ocn }}=0.88 \times \tau_{a t m}$. In the case of more mature decaying waves we choose $T=11 \mathrm{~s}$ and $u_{*} c_{p}^{-1}=0.03$ corresponding to $d_{s} d_{e}^{-1}=0.98$ and we use $\tau_{\text {ocn }}=1.12 \times \tau_{\text {atm }}$.

Figure 3 compares the solutions for growing and decaying waves scenarios (left and right columns, respectively) of the classical Ekman problem (i.e., Equation 15 with $\boldsymbol{u}_{s}=0$ and $\tau_{\text {ocn }}=\tau_{\text {atm }}$, in red) against the ones of the Ekman problem modified to include (i) only the CSF term (i.e., Equation 15 with $\tau_{\text {ocn }}=\tau_{a t m}$, in lightblue), (ii) only a sea-state dependent water-side momentum flux (i.e., Equation 15 with $\boldsymbol{u}_{s}=0$, in green) and iii) both wave feedbacks (i.e., the complete Equation 15, in black).

In both scenarios, the CSF term changes the direction of the ageostrophic upper ocean current vectors adding an additional veering with respect to the pure Ekman solution (compare light-blue and red lines in Figure 3). However, in the case of mature decaying wind-waves the impact seems to be greater. This can be explained considering that during severe storms the wave period can grow up to $\approx 10-12 s$ (Toffoli $\&$ Bitner-Gregersen, 2017), deepening the Stokes depth and resulting in $d_{s} d_{e}^{-1} \rightarrow 1$; in such a case, the Stokes component can have an exponentially decaying vertical contribution that is approximately of the same extent as the Ekman term. Conversely, when waves are growing and the Stokes depth is significantly shallower than the Ekman depth $\left(d_{s} d_{e}^{-1} \rightarrow 0\right)$ the contribution of the Stokes component becomes less relevant: in this case, the Eulerian velocity results mainly from the balance between the wind-driven and the Ekman-Stokes components of the total solution (see Polton et al., 2005 for the details).

Using only a sea-state dependent surface stress has the effect of simply increasing (decreasing) the magnitude of the Eulerian transport with respect to the classical Ekman solution when considering decaying (growing) waves, with no effect on the ocean current directions (see red and green arrows in Figure 3).

When combining the two wave-induced effects, ageostrophic upper ocean currents of both scenarios appear to be mainly influenced by the Coriolis-Stokes acceleration and only slightly modulated by the wave-dependent surface momentum flux. In the case of growing waves, the reduced surface stress drives the weakening of the wind-driven part of the total solution while the Ekman-Stokes component is slightly enhanced, resulting in the CSF and wave-dependent surface stress acting in synergy to deflect the direction of upper ocean currents. To the contrary, when waves are decaying the increased surface stress enhances the wind-driven component of the solution while the Ekman-Stokes part is relatively weakened, with the two wave effects that in this case seems to compete.

While the wave-modified Ekman model can be a useful tool to investigate and isolate some of the mechanisms underpinning the interaction between wind-driven currents and surface wind-waves, it is an idealized model unable to give a detailed and realistic representation of the complex upper ocean dynamics, especially for regions where the tidal regime is a leading order process, as it is the case for the NWS.

\section{Results}

\subsection{Assessment of the Lagrangian Modeling Approach}

The motion of an object floating on the sea surface and not fully submerged can be importantly affected by the wind leeway (Christensen et al., 2018). However, it is not clear yet how to properly include this process when simulating drifter trajectories (e.g., Breivik \& Allen, 2008; Callies et al., 2017; De Dominicis 

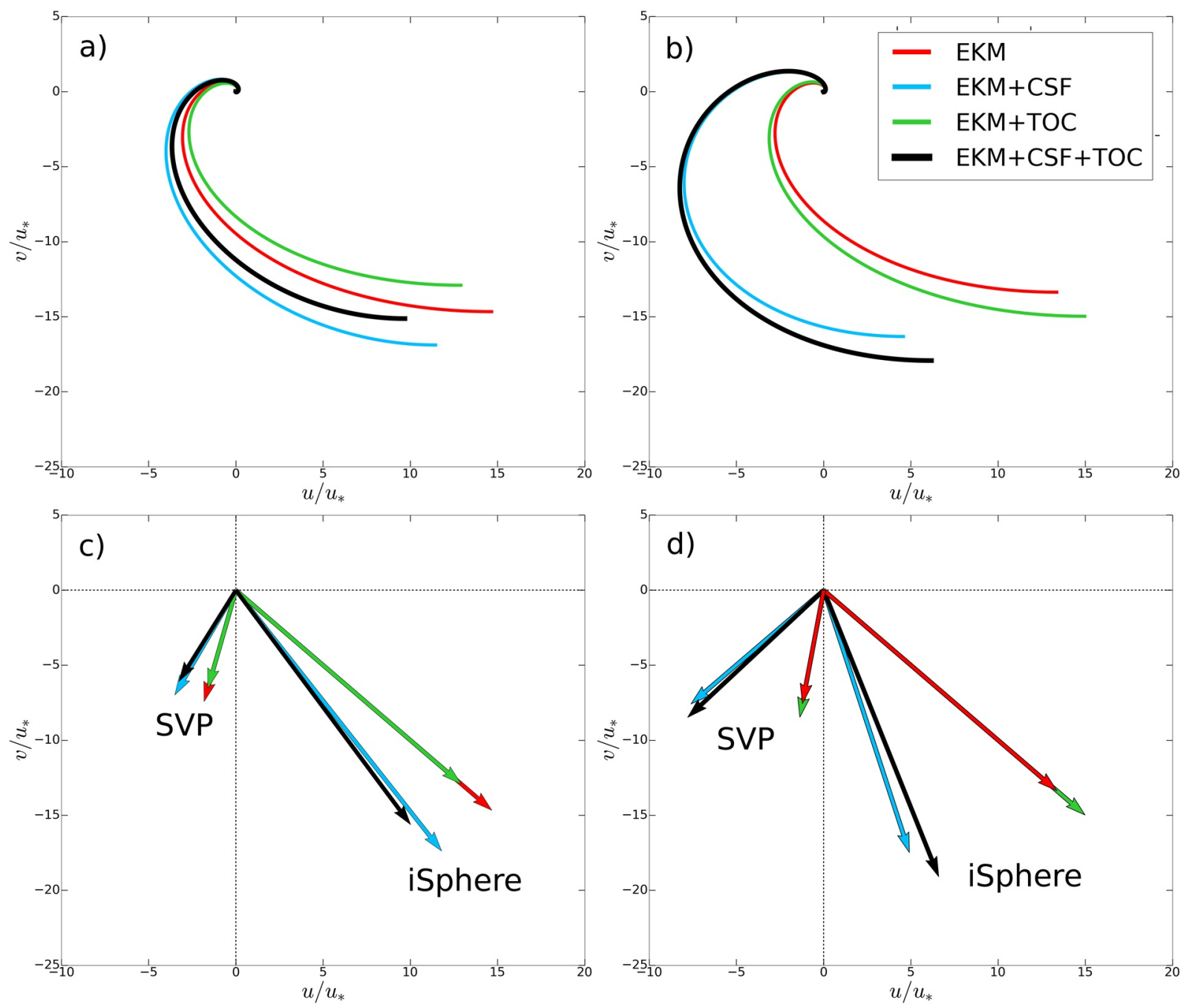

Figure 3. Solutions of the classical Ekman problem (in red) and the Ekman problem modified to include only the Coriolis-Stokes forcing (in light-blue), only a wave-dependent momentum flux (in green) and both wave feedbacks (in black). The idealized problem considers a zonal wind stress and monochromatic deep-water surface waves propagating in the same direction (see the text for the details). The upper panels present hodographs for the growing waves (a) and the decaying waves scenario (b). Panels (c and d) present the total Eulerian transport an iSphere and a Surface Velocity Program (SVP) drifter would experience (i.e., the Eulerian transport at the surface and in the depth-layer 10-20 m) for growing and decaying waves. All the velocities are normalised by the air-side friction velocity $\boldsymbol{u}_{*}$

et al., 2016; Röhrs et al., 2012; Staneva et al., 2021; Sutherland et al., 2020). In addition, studies on modeling the trajectory of SVP drifters are scarce (e.g., Abascal et al., 2012; Amemou et al., 2020; Kjellsson \& Doos, 2012), especially during storm conditions. Therefore the aim of this section is to assess the skills and the realism of our Lagrangian modeling approach.

The 49 drifter trajectories identified in Section 2.3 were simulated forcing the Lagrangian model with ocean currents $\boldsymbol{u}$ and Stokes drift $\boldsymbol{u}_{s}$ data from the CTR and CPL trial datasets. Table 3 presents the average skill score $\overline{s s}$ and associated standard error of simulations of iSphere and SVP drifters located either on the shelf or in open ocean waters. Averaging was carried out including simulations forced with both CTR and CPL trial datasets.

The average skill score of SVP drifters is $0.46 \pm 0.24$, with open ocean simulations presenting a $\overline{s s}$ of $0.44 \pm 0.25$ and on-shelf tracks showing a $\overline{s s}$ equal to $0.58 \pm 0.14$. It is not clear whether this difference in skill score between deep and shallow areas might depend on the relatively low number of available drifters on the shelf - 2 against 16 in the open ocean. The visual inspection of model results might help to gain 
Table 3

Average Skill Score $\overline{S S}$ and Associated Standard Deviation SD of

Numerical iSphere and SVP Tracks Located on the Shelf and in the Open Ocean. In the Case of iSpheres Simulations the Impact of Using the Wind Leeway is Also Assessed. Averaging Includes Simulations Forced With Both CTR and CPL Trial Datasets

\begin{tabular}{|c|c|c|c|c|}
\hline \multirow{2}{*}{$\begin{array}{l}\text { Drifter } \\
\text { type }\end{array}$} & \multirow[b]{2}{*}{ Region } & \multirow{2}{*}{$\begin{array}{c}\text { Numb. of } \\
\text { drifters }\end{array}$} & \multicolumn{2}{|c|}{$\overline{s s} \pm \mathrm{SD}$} \\
\hline & & & no-wind & wind \\
\hline \multirow[t]{2}{*}{ iSphere } & shelf \& shelf-break & 10 & $0.80 \pm 0.09$ & $0.42 \pm 0.12$ \\
\hline & open ocean & 21 & $0.54 \pm 0.20$ & $0.60 \pm 0.20$ \\
\hline \multirow[t]{2}{*}{ SVP } & shelf \& shelf-break & 2 & $0.58 \pm 0.14$ & - \\
\hline & open ocean & 16 & $0.44 \pm 0.25$ & - \\
\hline
\end{tabular}

Abbreviation: SVP, Surface Velocity Program. some more insights on this. Figures $4 a-4 d$ and Figures $6 a, 6 b, 6 e$, and $6 f$ present examples of open ocean and on-shelf SVP tracks simulated using $\boldsymbol{u}$ and $\boldsymbol{u}_{s}$ data from an uncoupled system (magenta and light-blue lines in Figures 4 and 6, respectively) or an ocean-wave coupled run (violet and red lines in Figures 4 and 6, respectively). Both on-shelf and open ocean numerical SVPs are consistently slower and generally deflected in comparison with the measured ones, an indication that the generally poor $(<0.5) \overline{s s}$ of SVPs might depend on inaccuracies not directly related to the wave effects included in the coupling. For example, the systematic underestimation of SVP drifters velocity might suggest a lack of storm-related physical processes which may promote an enhanced drifter transport, such as the influence of strong storm-winds below the surface or SVPdrogued drifters surfing large storm-waves. Another possibility could be that the ocean model might underestimate the Ekman propagation of surface wind effects down into the water column (for example by overestimating the vertical shear), resulting in too slow sub-surface currents.

In the case of iSphere drifters, open ocean and on-shelf simulations present different sensitivity to the wind leeway. In deep water areas, including the wind drag velocity $\left(\boldsymbol{u}_{w}>0\right)$ in the Lagrangian transport Equation 11a generally allows to reduce the underestimation of the observed trajectories (see Figures $4 \mathrm{e}$ and $4 \mathrm{~h}$ ), improving the average skill score from $0.54 \pm 0.20$ to $0.60 \pm 0.20$. On the other hand, including the wind leeway in coastal areas generates too large drifter velocities causing overshooting of the final observed locations (e.g., Figures $4 \mathrm{f}$ and $4 \mathrm{~g}$ ) while using $\boldsymbol{u}_{w}=0$ (i.e., no wind drag velocity) significantly improves the simulations' skill increasing the $\overline{s s}$ from $0.42 \pm 0.12$ to $0.80 \pm 0.09$. However, iSphere simulations generally present a good $(>0.5)$ average skill score (the $\overline{s s}$ with the wind leeway is $0.58 \pm 0.22$ while the one without is $0.61 \pm 0.21$ ), suggesting that ocean and wave-induced currents may represent the main forcing for the surface Lagrangian transport.

In order to better understand the reason behind the negative impact of the wind leeway in shelf areas, the accuracy of surface ocean currents, Stokes drift and wind velocities used to force the Lagrangian model was assessed against on-shelf independent observations.

Available wind speed measurements during the four storms were recorded by two wave buoys of the World Meteorological Organisation - International Oceanographic Commission (WMO-IOC) Joint Commission for Oceanography Marine Meteorology's operational Wave Forecast Verification Scheme (JCOMM-WFVS, Bidlot et al., 2007), which includes quality controlled in-situ observations sampled on a 6-hourly basis. One buoy was located near the shelf-break off North Ireland coast while the other was off Land's End coast (respectively buoy A and B in Figure 5a). Figures 5b and 5c compare time-series of wind speed measurements during the four storms at buoy A and B, respectively, with time-series of 3-hourly ECMWF wind speed interpolated at the same locations. At buoy A, modeled wind speeds seem to overestimate the observations, with a BIAS of $1.49 \mathrm{~m} \mathrm{~s}^{-1}$ and a RMSE of $2.38 \mathrm{~m} \mathrm{~s}^{-1}$, while at buoy B ECMWF wind speeds are slower than the measured ones, with BIAS $=-1.32 \mathrm{~m} \mathrm{~s}^{-1}$ and RMSE $=2.1 \mathrm{~m} \mathrm{~s}^{-1}$. It is worth noting that for both buoys there is no metadata to confirm whether or how these data are corrected to a $10 \mathrm{~m}$ wind speed. Consequently, quantitative errors may have significant uncertainties.

HF-radar currents measured in an area off the north coast of the south-west of England (see rectangle in Figure 5a) were used to assess the accuracy of on-shelf surface ocean currents and Stokes drift during the four storms. The Wave Hub HF radar system is a phased-array WEllen RAdar (WERA) system which has been measuring waves and currents off the north coast of Cornwall since 2011 (Lopez \& Conley, 2019). Comparisons between radar surface current measurements and ADCP derived near surface measurements typically exhibit a bias less than $0.03 \mathrm{~m} \mathrm{~s}^{-1}$ and RMSE less than $0.10 \mathrm{~m} \mathrm{~s}^{-1}$ (Lopez, 2017). Whilst radar-derived currents are extensively used for oceanographic studies in coastal regions (e.g., Lopez et al., 2020; Paduan \& Washburn, 2013), whether they include either the entire wave-induced Stokes drift, part of it or none of it is still an open question (e.g., Isern-Fontanet et al., 2017). After sensitivity tests, it was decided to compare HF-radar derived surface currents against the linear combination of model ocean currents 

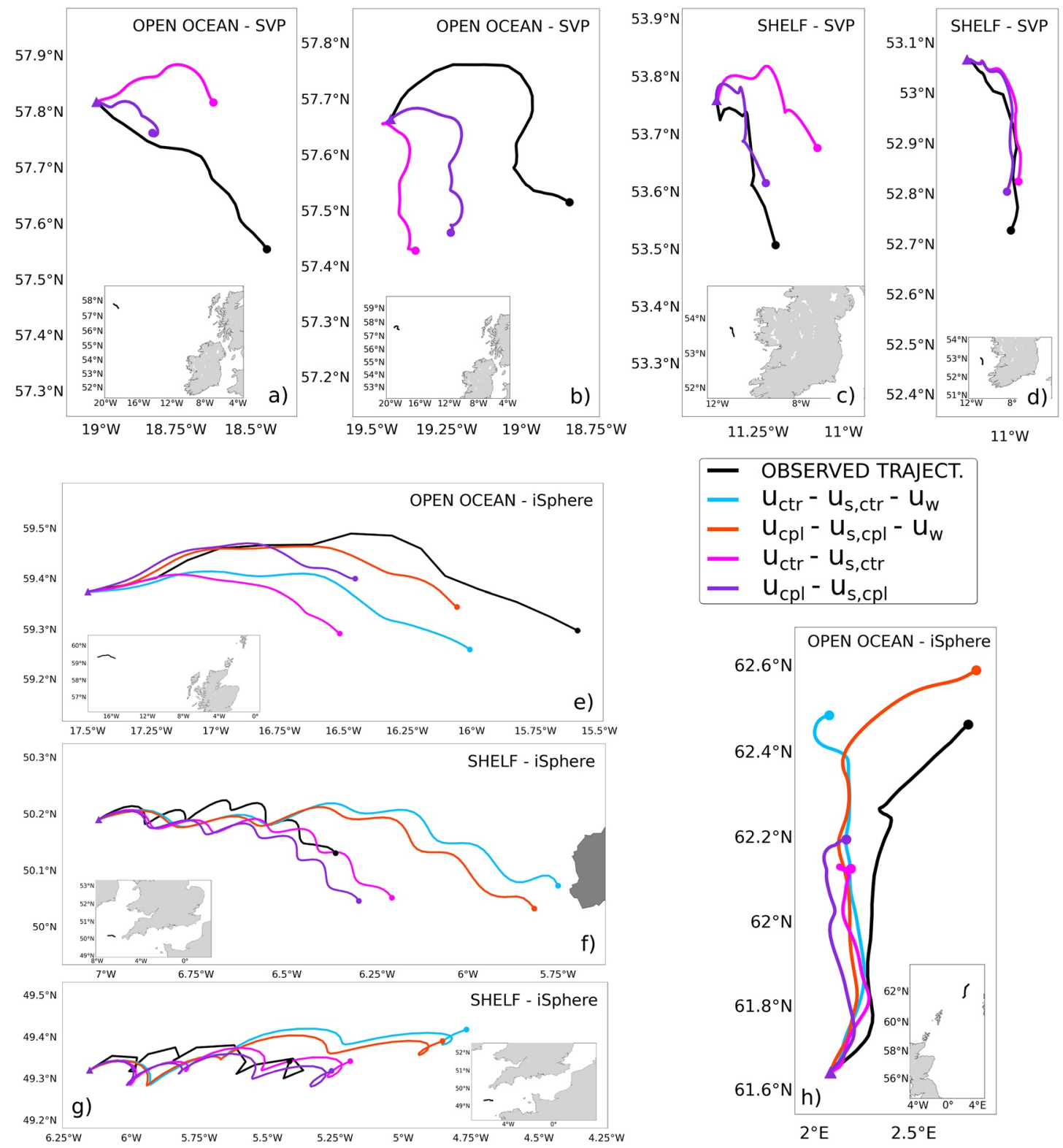

Figure 4. Examples of simulations of Surface Velocity Program (SVP) and iSphere drifters located open ocean and on the shelf during the four storms considered in this study. Observed drifter tracks are shown in black. Drifter trajectories simulated forcing the Lagrangian model only with the ocean surface dynamics $\left(\boldsymbol{u}+\boldsymbol{u}_{s}\right)$ from CTR and CPL trials are shown in magenta and violet, respectively. Tracks simulated using the wind leeway combined with surface currents and wave-induced transport $\left(\boldsymbol{u}+\boldsymbol{u}_{s}+\boldsymbol{u}_{w}\right)$ from CTR and CPL runs are presented in light-blue and red, respectively.

and Stokes drift. The analysis considered only HF-radar currents with an associated error $<0.09 \mathrm{~m} \mathrm{~s}^{-1}$ (see Figures $5 \mathrm{~d}, 5 \mathrm{e}, 5 \mathrm{f}$, and $5 \mathrm{~g}$ for snapshots of radar derived surface currents during the four storms with such an accuracy) and included the computation of spatially averaged BIAS, RMSE and veering angles $\theta$ (Kun$\mathrm{du}, 1976$ ) for each storm. Table 4 presents storm averaged metrics of surface ocean currents and Stokes drift from CTR and CPL trials. In general, the surface dynamics simulated by the CPL run presents improved accuracy (total metrics are BIAS $=-0.04 \mathrm{~m} \mathrm{~s}^{-1}$, RMSE $=0.10 \mathrm{~m} \mathrm{~s}^{-1}$ and $\theta=-0.6^{\circ}$ ) in comparison to the one of the CTR experiment (BIAS $=-0.09 \mathrm{~m} \mathrm{~s}^{-1}$, RMSE $=0.17 \mathrm{~m} \mathrm{~s}^{-1}$ and $\theta=3.35^{\circ}$ ).

Assessment against independent observations showed that modeled wind data might be affected by large inaccuracies in shelf and coastal areas. This is in agreement with other studies. For example, a recent work by Christakos et al. (2020) investigated the relationship between the quality of wind fields in the proximity of a coast with complex orography and the mesh size of the atmospheric model. They found that, especially 

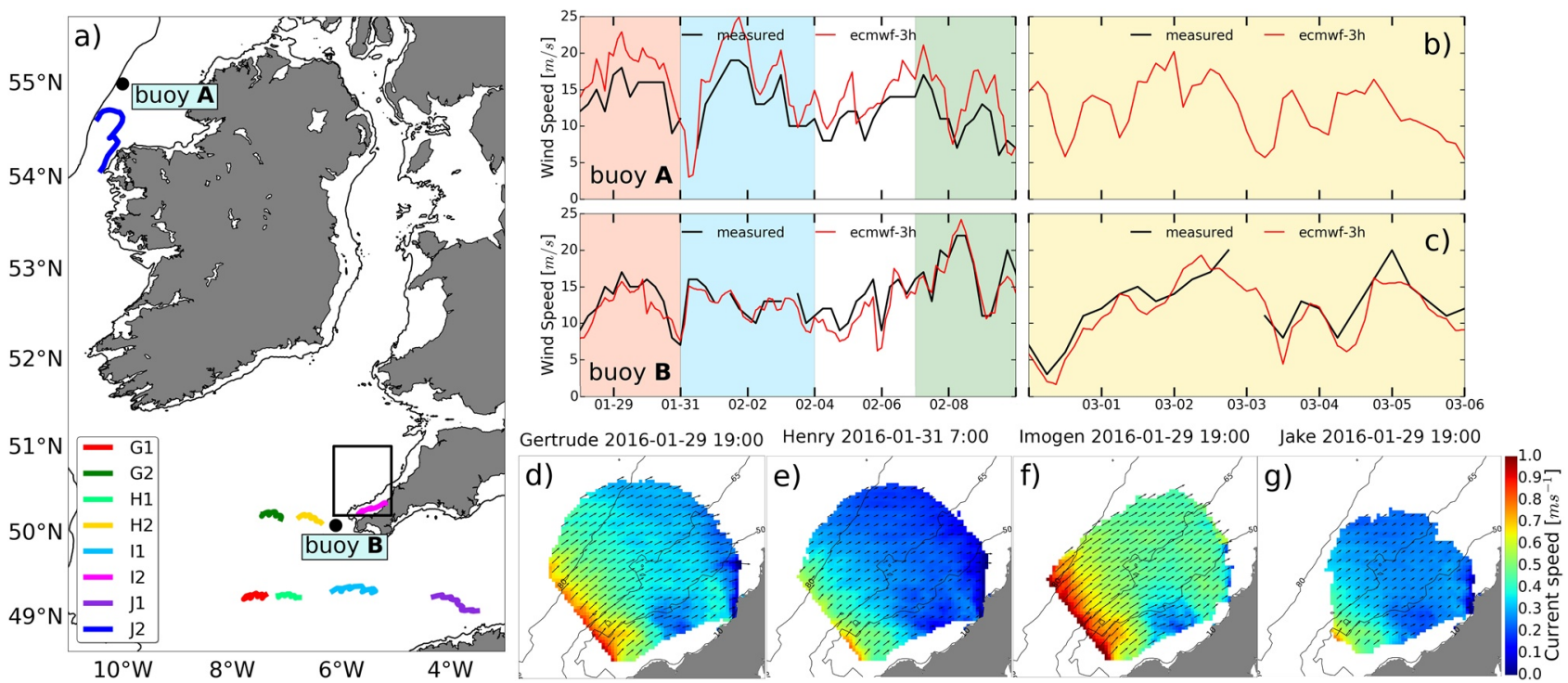

Figure 5. (a) On-shelf iSphere drifter trajectories observed during storms Gertrude (G1, G2), Henry (H1, H2), Imogen (I1, I2) and Jake (J1, J2) together with the location of buoys A and B. The area covered by HF-radar measurements is also shown with the rectangle in black. (b and c) Time-series of wind speed measured (black) during the four storms at buoy A and B, respectively, against time-series of 3-hourly European Centre for Medium-Range Weather Forecasts (ECMWF) wind speed interpolated at the same locations (red). Storm-windows are identified by colored shadows: pink is for Gertrude, light-blue for Henry, green for Imogen and yellow for Jake. (d-g) Snapshots of HF-radar surface currents maps detected during the four storms. Only HF-radar measurements with an associated error $<0.09 \mathrm{~m} \mathrm{~s}^{-1}$ are shown.

during extreme wind events, a finer grid can better capture local wind phenomena but leads to an overestimation of the wind speed while a coarser mesh systematically simulates weaker winds along the coast. Also, Staneva et al. (2021) noted that adding the contribution of windage in coastal areas might lead to over-parameterization. Therefore, in this study the trajectories of on-shelf iSphere drifters were simulated not taking into account the leeway of the wind (i.e., using $u_{w}=0$ ).

\subsection{The Impact of Ocean-Wave Coupling}

In this section we evaluate and analyze the impact of the three wave feedbacks included in the FOAMAMM15 coupled system on the upper ocean dynamics during storm conditions.

Four different Lagrangian experiments were conducted (see Table 5) forcing OpenDrift model with ocean and wave data from CTR and CPL trial datasets to simulate the 49 drifter tracks identified in Section 2.3. Two experiments used $\boldsymbol{u}$ and $\boldsymbol{u}_{s}$ data extracted from the same trial data set and, consequently, they were named as $U_{c t r} S_{c t r}$ and $U_{c p l} S_{c p l}$, respectively. The other two experiments were named $U_{c t r} S_{c p l}$ and $U_{c p l} S_{c t r}$ since they forced the Lagrangian simulations combining $\boldsymbol{u}$ data from one data set with $\boldsymbol{u}_{s}$ data from the other one. In the case of open ocean iSpheres, the Lagrangian simulations were forced using also the wind leeway.

\section{Table 4}

Spatially and Storm Averaged BIAS, RMSE and Veering Angles $\theta$ of Linearly Combined Surface Ocean Currents and Stokes Drift From CTR and CPL Trials With Respect to HF-Radar Detected Surface Currents

\begin{tabular}{|c|c|c|c|c|c|c|c|c|}
\hline \multirow[b]{2}{*}{ Metric } & \multicolumn{2}{|c|}{ Gertrude } & \multicolumn{2}{|c|}{ Henry } & \multicolumn{2}{|c|}{ Imogen } & \multicolumn{2}{|c|}{ Jake } \\
\hline & CTR & CPL & CTR & CPL & CTR & CPL & CTR & CPL \\
\hline BIAS $\left[m s^{-1}\right]$ & -0.09 & -0.05 & -0.09 & -0.03 & -0.10 & -0.05 & -0.07 & -0.02 \\
\hline $\operatorname{RMSE}\left[m s^{-1}\right]$ & 0.18 & 0.10 & 0.16 & 0.08 & 0.21 & 0.13 & 0.14 & 0.08 \\
\hline$\theta\left[^{\circ}\right]$ & -0.60 & -1.10 & 9.75 & 3.20 & -1.62 & -2.60 & 4.61 & -1.80 \\
\hline
\end{tabular}

Note. A positive $\theta$ means that the vector sum $\boldsymbol{u}+\boldsymbol{u}_{\mathrm{s}}$ veers clockwise with respect to HF-radar currents. 
Table 5

Average Skill Score $\overline{\text { sS }}$ and Standard Deviation SD of Open Ocean and On-Shelf iSphere and SVP Drifters for the Four Lagrangian Experiments

\begin{tabular}{llccccc}
\hline & & \multicolumn{4}{c}{$\overline{s s} \pm \mathrm{SD}$} \\
\cline { 4 - 7 } Drifter type & \multicolumn{1}{c}{ Region } & Numb. of drifters & $U_{c t r} S_{c t r}$ & $U_{c p l} S_{c p l}$ & $U_{c t r} S_{c p l}$ & $U_{c p l} S_{c t r}$ \\
\hline \multirow{2}{*}{ iSphere } & shelf \& shelf-break & 10 & $0.76 \pm 0.09$ & $0.82 \pm 0.09$ & $0.75 \pm 0.10$ & $0.81 \pm 0.09$ \\
& open ocean & 21 & $0.57 \pm 0.21$ & $0.60 \pm 0.19$ & $0.55 \pm 0.21$ & $0.59 \pm 0.20$ \\
\multirow{3}{*}{ SVP } & shelf \& shelf-break & 2 & $0.50 \pm 0.16$ & $0.66 \pm 0.05$ & $0.47 \pm 0.16$ & $0.69 \pm 0.05$ \\
& open ocean & 16 & $0.43 \pm 0.23$ & $0.46 \pm 0.27$ & $0.42 \pm 0.23$ & $0.46 \pm 0.26$ \\
\hline
\end{tabular}

Note. $U_{c t r} S_{c t r}$ and $U_{c p l} S_{c p l}$ simulations use ocean currents and stokes drift from CTR and CPL trials, respectively; $U_{c t r} S_{c p l}$ experiment uses currents from the CTR trial and the stokes drift from the CPL data set while $U_{c p l} S_{c t r}$ uses currents from the CPL data set and the stokes drift from the CTR trial.

Abbreviation: SVP, Surface Velocity Program.

Table 5 presents the average skill score $\overline{s s}$ and standard deviation SD of iSphere and SVP drifters on-shelf and in the open ocean for the four Lagrangian experiments. The comparison between the average skill scores of $U_{c t r} S_{c t r}$ and $U_{c p l} S_{c p l}$ experiments show that on average, during severe storm events, ocean-wave coupling is able to improve the accuracy of the predicted surface dynamics by $4 \%$ (from $0.56 \pm 0.23$ to $0.60 \pm 0.24$ ). Improvements for specific drifters can reach values of $\approx 15-20 \%$.

In addition, numerical results show that during storm events ocean-wave coupling seems to have a similar impact on both type of drifters, improving the $\overline{s s}$ of surface iSpheres from $0.63 \pm 0.20$ to $0.67 \pm 0.19$ and the one of $15 \mathrm{~m}$ drogued SVPs from $0.43 \pm 0.22$ to $0.48 \pm 0.26$. Generally, the three wave feedbacks included in the FOAM-AMM15 coupled system predominantly act at the sea surface and significantly decay with the depth. However, our results appear to indicate that during severe sea states their effect may propagate below the surface and affects also the sub-surface ocean dynamics.

In the following two sections we deepen our analysis investigating the relative impact of coupling on ocean currents and Stokes drift.

\subsubsection{The Effect of Coupling on the Ocean Currents}

The impact of ocean-wave coupling on the accuracy of the upper ocean currents can be evaluated and quantified considering Lagrangian experiments applying the same Stokes drift forcing but using different data for the currents, i.e., comparing $U_{c t r} S_{c t r}$ against $U_{c p l} S_{c t r}$ and $U_{c t r} S_{c p l}$ against $U_{c p l} S_{c p l}$, respectively.

Figure 6 shows that, as expected, ocean-wave coupling has the larger impact on the ocean currents (compare light-blue against green and yellow against red trajectories). In addition, results reported in Table 5 reveal that using currents from a coupled system allows the improvement of the $\overline{s s}$ by $8 \%$ in shelf areas (from $0.71 \pm 0.14$ to $0.79 \pm 0.09$ ) and $4 \%$ in the open ocean (from $0.50 \pm 0.23$ to $0.54 \pm 0.24$ ). The greater improvement on the shelf is probably the consequence of multiple factors. First, there is an under-sampling affecting on-shelf regions - 12 tracks against 37. Then, including the wind leeway in the forcing of off-shelf simulations could result in masking the effect of ocean-wave coupling, making improvements less notable. Finally, the interaction between waves, tides, and wind-driven circulation is a leading order process on the shelf, where ocean waves increase their amplitude to conserve energy flux and tidal currents are larger than in the open ocean (e.g., Huthnance, 1981; Simpson, 1998; Valiente et al., 2019).

In order to better understand the mechanisms behind the difference in skill score between shelf and open ocean simulations, we continue our analysis computing a number of simulated diagnostics along the 49 observed trajectories using model outputs from CTR and CPL trial datasets.

Figure 7a compares the track-averaged magnitude of current velocities $\langle u\rangle$ and Stokes drift $\left\langle u_{s}\right\rangle$ at the surface (iSpheres) or $15 m$ (SVPs). In the case of SVP drifters, ocean currents are consistently larger than the Stokes drift, with values from $\approx 2$ to $\approx 10$ times larger, in agreement with the strong vertical shear characterizing the Stokes drift (e.g., Breivik et al., 2014, 2016). However, results suggest that in the presence of 

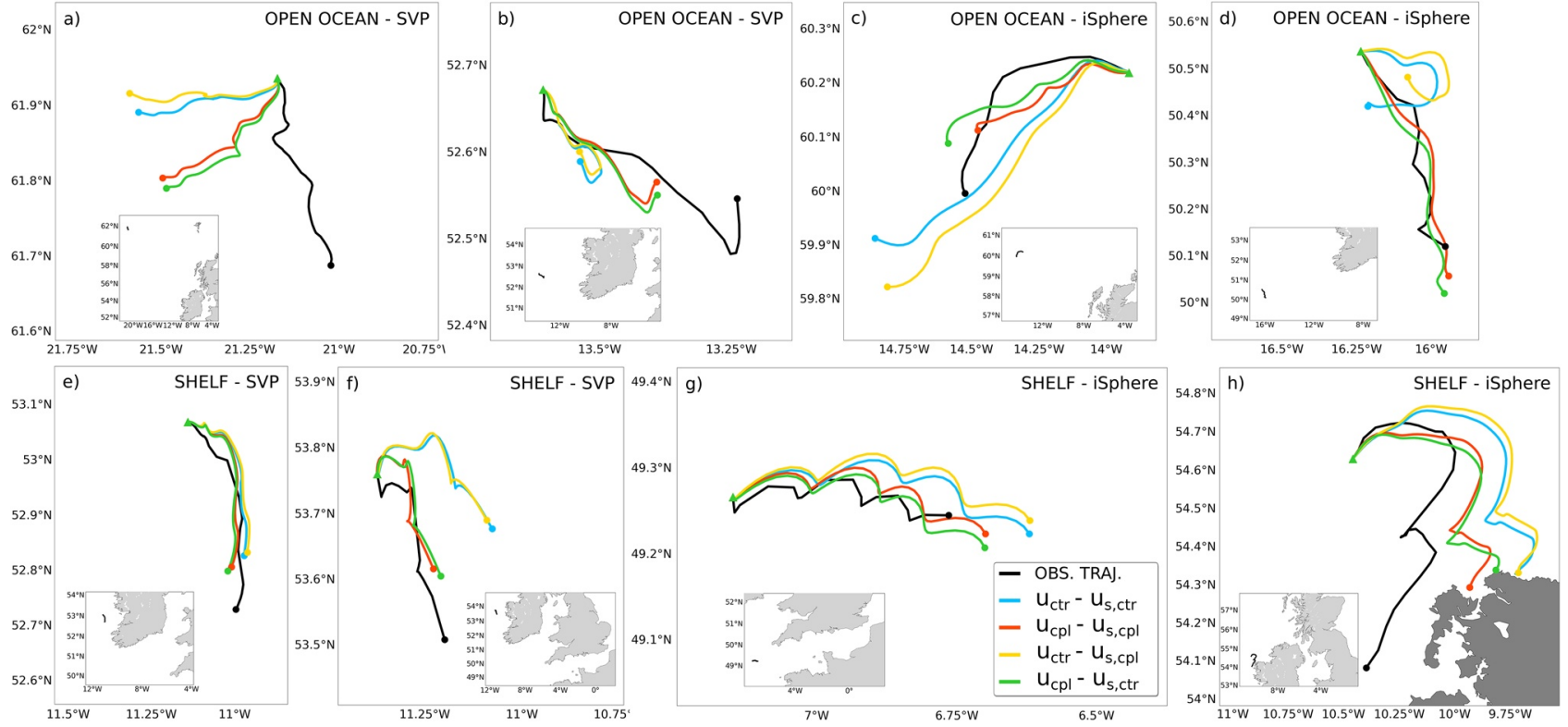

Figure 6. Examples of Surface Velocity Program (SVP) and iSphere simulations located in the open ocean and on the shelf during the four storms considered in this study. Observed drifter tracks are shown in black. Drifter trajectories simulated forcing the Lagrangian model with the ocean surface dynamics ( $\boldsymbol{u}$ and $\left.\boldsymbol{u}_{s}\right)$ from CTR and CPL trials are shown in light-blue $\left(U_{c t r} S_{c t r}\right)$ and red $\left(U_{c p l} S_{c p l}\right)$, respectively. Tracks simulated using ocean currents from CTR trial and Stokes drift from CPL data set are shown in yellow $\left(U_{c t r} S_{c p l}\right)$; simulations using ocean currents from CPL trial and Stokes drift from CTR data set are shown in yellow $\left(U_{c p l} S_{c t r}\right)$. Open ocean iSphere simulations use also the wind leeway $\boldsymbol{u}_{w}>0$.

wind-storms the contribution of the wave-induced transport to the total drift below the surface might be important. In the case of iSpheres, $70 \%$ of on-shelf drifters present track-averaged ocean currents generally larger than the Stokes drift while in the open ocean the majority of the trajectories $(81 \%)$ are affected by larger wave-induced velocities $\left\langle u_{s}\right\rangle$. This seems to support the idea that one of the reasons for the larger improvements on the shelf relative to off-shelf might be the stronger ocean currents characterizing shallow areas.

In order to understand the physical mechanism behind the differences in the currents forcing our drifters, we apply the Doodson filter (Parker, 2007) to the hourly ocean currents model outputs to remove diurnal and sub-diurnal signals and compute the residual flow $\boldsymbol{u}_{r}$. Figure 8 presents the frequency spectrum of the high-frequency oceanic flow $\tilde{\boldsymbol{u}}=\boldsymbol{u}-\boldsymbol{u}_{r}$ at the surface computed for three stations located in deep waters (stations S1 and S2 in the map in Figure 8) and on the shelf (station S3). In our domain of study, the
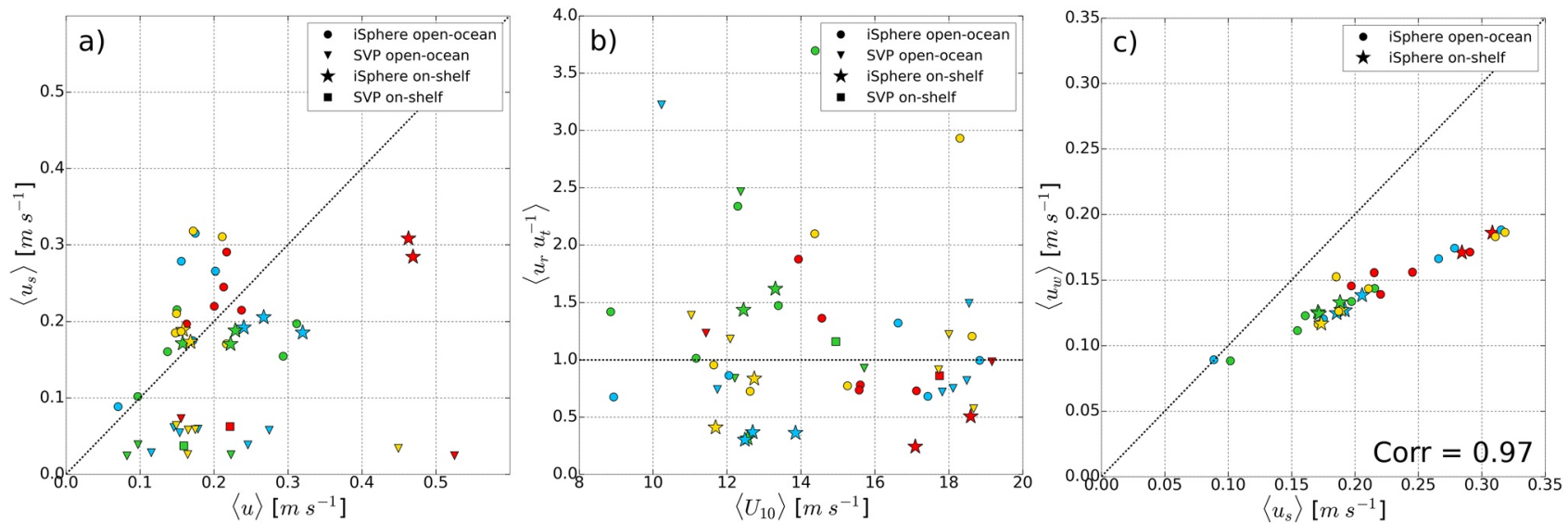

Figure 7. Track-averaged magnitude of (a) current velocities $\langle u\rangle$ and Stokes drift $\left\langle u_{s}\right\rangle$, (b) ratio between residual and tidal currents $\left\langle u_{r} \tilde{u}^{-1}\right\rangle$ and wind speed $\left\langle U_{10}\right\rangle$, (c) surface Stokes drift and wind leeway for open ocean and on-shelf surface (iSpheres) or $15 \mathrm{~m}$ Surface Velocity Program (SVPs) drifters. 


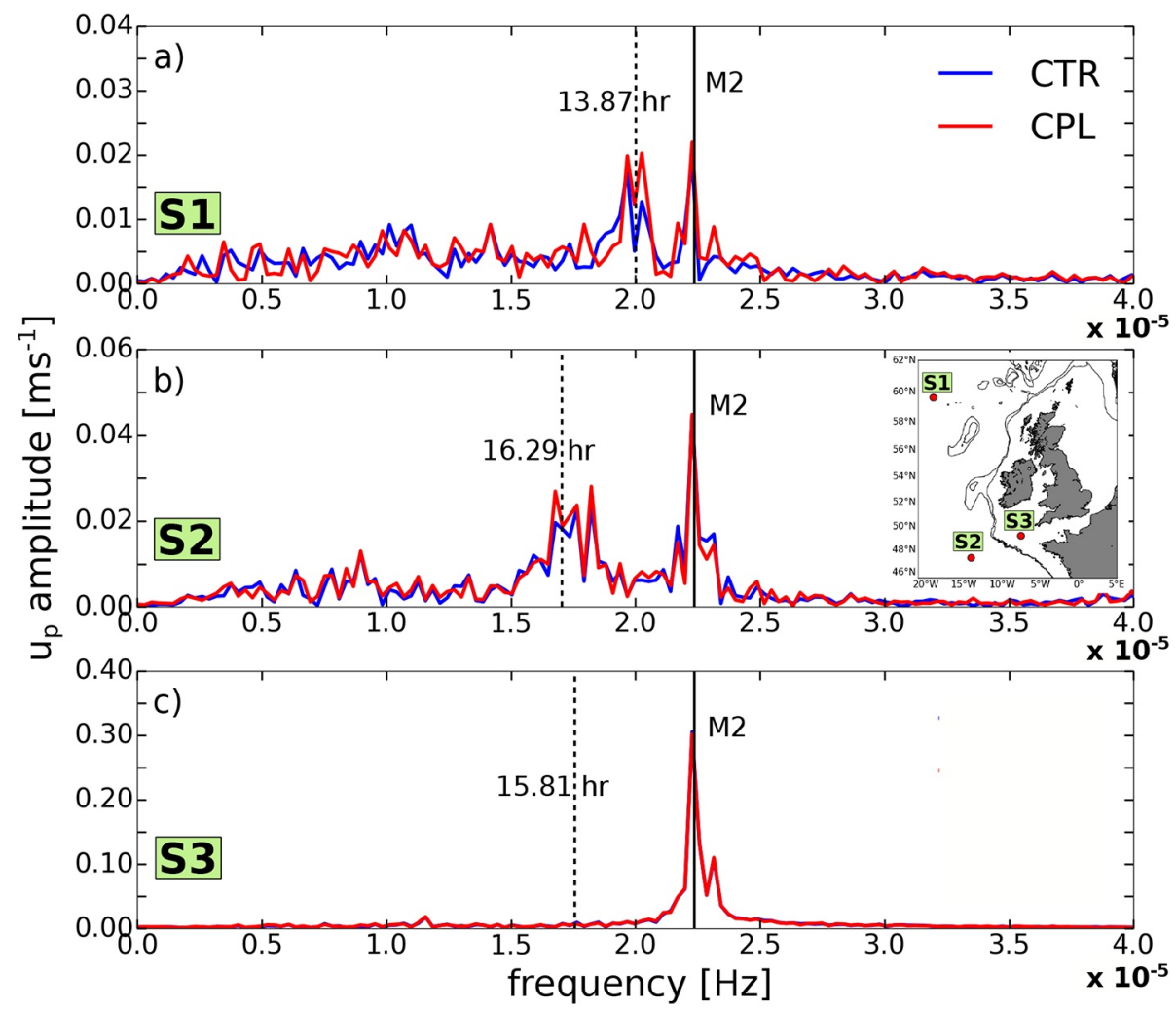

Figure 8. Frequency spectrum of the zonal component of $\tilde{\boldsymbol{u}}=\boldsymbol{u}-\boldsymbol{u}_{r}$ velocity at the surface computed for three stations located in the open ocean (stations S1 and S2 in the inset) and on the shelf (station S3) for the period from 01-01-2016 to $10-02-2016$.

inertial period ranges between $\approx 13.5$ and $\approx 17.2 \mathrm{~h}$. Figures $8 \mathrm{a}$ and $8 \mathrm{~b}$ show clear inertial and $M_{2}$ maxima, indicating that in the open ocean $\tilde{\boldsymbol{u}}$ includes both tidal and mesoscale currents with modest amplitudes of comparable magnitude $\left(\approx 0.02-0.05 \mathrm{~m} \mathrm{~s}^{-1}\right)$. Conversely, inertial oscillations are not present on the shelf and the strong high-frequency flow $\tilde{\boldsymbol{u}}$ is largely tidal with amplitude of $\approx 0.3 \mathrm{~m} \mathrm{~s}^{-1}$ as shown in Figure $8 \mathrm{c}$. This is probably a consequence of the strong dissipative processes characterizing shallow areas which suppress the development of inertial waves (Stanev \& Ricker, 2020). Since barotropic tidal currents are generally more predictable than the fully baroclinic mesoscale circulation, these results may help also to explain why, on average, Lagrangian simulations (with or without coupling) are more skilful on the shelf than in the open ocean. In addition, velocity spectra reveals that ocean-wave coupling affects mesoscale currents while it has practically no effect on the $M_{2}$ tidal component.

Figure $7 \mathrm{~b}$ presents the track-averaged ratio $\left\langle u_{r} \tilde{u}^{-1}\right\rangle$ as a function of the track-averaged wind speed $\left\langle U_{10}\right\rangle$. On the shelf, $25 \%$ of the drifters' trajectories are characterized by a ratio $\left\langle u_{r} \tilde{u}^{-1}\right\rangle>1$, while in the deep ocean this happens for the $54 \%$ of the tracks. In addition, the track-averaged wind speed is larger than $14 \mathrm{~m} \mathrm{~s}^{-1}$ for $56 \%$ of the drifters' tracks in the open ocean while the large majority of on-shelf trajectories (77\%) are affected by a $\left\langle U_{10}\right\rangle<14 \mathrm{~m} \mathrm{~s}^{-1}$. These results show that, during our four storms, the on-shelf upper ocean flow is generally tidally dominated whereas in the open ocean the residual component seems to lead the dynamics.

Figure $7 \mathrm{c}$ compares the track-averaged magnitude of the surface Stokes drift and the wind leeway in the case of iSphere drifters. For all the trajectories, the wind leeway is less relevant than the Stokes drift, indicating that tidal, wind- and wave-driven currents represent the main forcing for both off- and on-shelf drifters. The high correlation $(r=0.97$ ) between the wind leeway and the Stokes drift might suggest that iSphere trajectories are generally forced by locally generated wind-waves. This conclusion seems to be supported also by the high Stokes drift values found in Figure 7a, since the surface Stokes drift is mainly driven by shorter high-frequency waves while the contribution of lower wavenumbers (i.e., swell) is generally much 

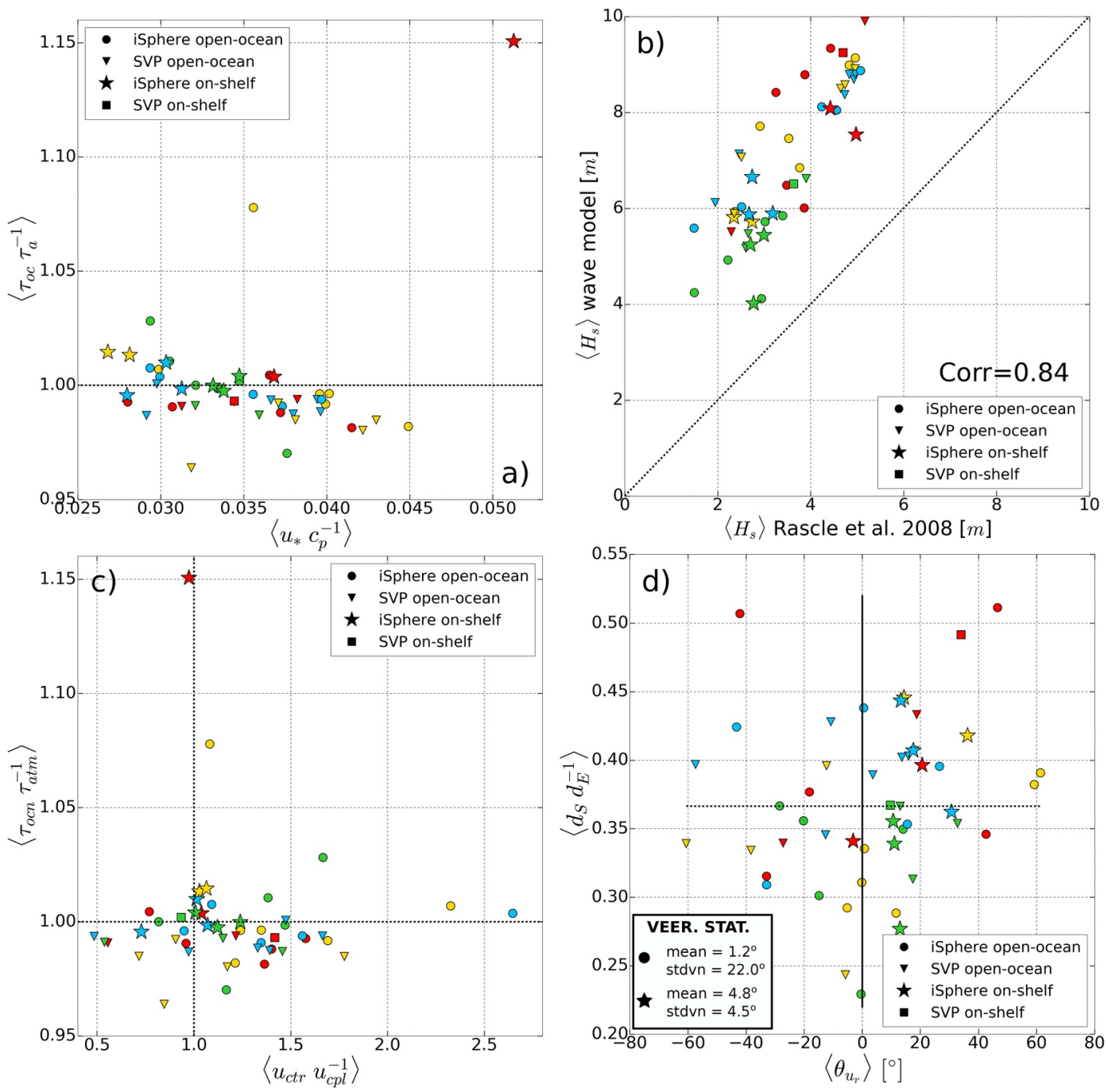

Figure 9. Track-averaged (a) $\left\langle\tau_{o c n} \tau_{\text {atm }}^{-1}\right\rangle$ ratio as a function of the average inverse wave age $\left\langle u_{*} c_{p}^{-1}\right\rangle$, (b) $\left\langle H_{s}\right\rangle$ estimated by the standalone ocean model against the $\left\langle H_{s}\right\rangle$ computed by the spectral wave model, (c) $\left\langle\tau_{\text {ocn }} \tau_{\text {atm }}^{-1}\right\rangle$ ratio as a function of the ratio $\left\langle u_{c t r} u_{c p l}^{-1}\right\rangle$, (d) ratio $\left\langle d_{s} d_{e}^{-1}\right\rangle$ and the veering $\theta_{u_{r}}$ of CPL residual currents with respect to the CTR residual flow computed according to Kundu (1976) for open ocean and on-shelf surface (iSpheres) or $15 m$ Surface Velocity Program (SVPs) drifters.

smaller (e.g., Breivik et al., 2014; Lenain \& Pizzo, 2020; Pizzo et al., 2019). Both results might also indicate that in the case of severe sea-states the wave-induced transport at the surface might be parameterized quite accurately as a function of the wind speed (e.g., Breivik \& Allen, 2008). In the case of the sub-surface wave-induced drift (i.e., the Stokes drift felt by SVPs), the same approach would probably be less accurate, since the low-frequency component of the wave energy spectra might be expected to have an important impact, especially for those scenarios where the wind is more benign but swell is present (e.g., Breivik \& Christensen, 2020).

Figure 9a presents the track-averaged ratio $\left\langle\tau_{\text {ocn }} \tau_{\text {atm }}^{-1}\right\rangle$ as a function of the average inverse wave age $\left\langle u_{*} c_{p}^{-1}\right\rangle$, where $c_{p}$ is the phase velocity of waves at the peak of the wind-sea spectrum (Melville et al., 2004), $u_{*}$ is the air friction speed and $u_{*} c_{p}^{-1} \rightarrow 0.1$ in the case of younger waves while for older waves $u_{*} c_{p}^{-1} \rightarrow 0$. As expected, all the drifters are affected by relatively developed waves. This is a consequence of the algorithm used to identify the drifter trajectories affected by the storms. However, in the open ocean $59 \%$ of the drifters are affected by waves with $u_{*} c_{p}^{-1}$ larger than the median value of the data while on the shelf this is true for only 
$16 \%$ of the tracks. In addition, $76 \%$ of open ocean trajectories present $\left\langle\tau_{\text {ocn }} \tau_{\text {atm }}^{-1}\right\rangle\langle 1$ and an average ratio of 0.99 while on the shelf for $58 \%$ of the tracks $\tau_{\text {ocn }}$ is larger than $\tau_{\text {atm }}$ and the average ratio is 1.03. Generally, both results seem to indicate that the open ocean might be affected by younger growing waves while on the shelf we might be in the presence of more developed decaying waves.

In the FOAM-AMM15 system, the sea surface roughness $z_{0}$ is computed as a function of the significant wave height $H_{s}$ : when the ocean model is run in standalone mode $H_{s}$ is parameterized from the wind speed following Rascle et al. (2008) while in coupled mode the $H_{s}$ is computed by the wave model (see Section 2.1.3 for the details). Figure $9 \mathrm{~b}$ compares the track-averaged $\left\langle H_{s}\right\rangle$ estimated according to Rascle et al. (2008) (i.e., Equation 4) against the $\left\langle H_{s}\right\rangle$ computed by the spectral wave model. Rascle et al. (2008) found that estimating the significant wave height $H_{s}$ from the wind speed might be a good approximation in the case of young wind-seas without swell, while it could lead to an underestimation of 10-20\% in the case of fully developed waves. The high correlation $(r=0.84)$ between the estimated and computed $H_{s}$ of our results seem to support those conclusions. However, our results also indicate that, during severe storm conditions, the parameterization used by the uncoupled ocean model might underestimate the $H_{s}$ computed by the spectral wave model by $30-50 \%$.

When modifying the water-side momentum flux or the sea surface roughness $z_{0}$, the result is that the speed of the upper ocean flow $u$ is changed. In order to understand the impact of both wave feedbacks on the magnitude of ocean currents, we continue our analysis computing the track-averaged ratio $\left\langle u_{c t r} u_{c p l}^{-1}\right\rangle$, where $u_{c t r}$ are ocean currents from the CTR trial while $u_{c p l}$ are the ones from the CPL run. Figure 9c shows that, in the open ocean, for $80 \%$ of iSphere and $56 \%$ of SVP tracks $u_{c t r}$ currents are larger than $u_{c p l}$, with a mean ratio of 1.50 and 1.40 , respectively. On the shelf, $80 \%$ of the iSpheres show $\left\langle u_{c t r} u_{c p l}^{-1}\right\rangle>1$, although with much smaller values - the mean ratio is equal to $1.07 .50 \%$ of the tracks of the on-shelf SVPs present $u_{c p l}$ larger than $u_{c t r}$ with a ratio of 0.94 .

The simplified analysis of Section 3 indicated that the magnitude of the Coriolis-Stokes veering might depend on the ratio between the Stokes' depth $d_{s}$ and the Ekman scale $d_{e}$. In order to verify whether this is the case also in a realistic scenario, we compute the track-averaged ratio $\left\langle d_{s} d_{e}^{-1}\right\rangle$ and $\left\langle\theta_{u_{r}}\right\rangle$, where $\theta_{u_{r}}$ is the veering of CPL residual currents with respect to the CTR residual flow computed according to Kundu (1976) - a positive $\theta_{u_{r}}$ signifies that the vector $\boldsymbol{u}_{r, c p l}$ veers clockwise with respect to $\boldsymbol{u}_{r, c t r}$. The Stokes' depth $d_{s}$ is calculated using the peak period of the wind-sea spectrum and the Fenton and McKee (1990) approximation. The length scale of neutrally stratified Ekman layers is usually estimated as $d_{e}=\gamma u_{* w} f^{-1}$, with $\gamma$ derived from observations (e.g., Perlin et al., 2007; Stigebrandt, 1985). In this work we use $\gamma=0.25$ (Coleman et al., 1990; McWilliams et al., 1997; Polton et al., 2005). Assuming constant vertical viscosity will always result in overestimating $d_{e}$, since stratification acts to inhibit turbulent mixing of momentum reducing the Ekman layer thickness (e.g., Cushman-Roisin \& Beckers, 2011). Figure 9d shows that 58\% of on-shelf tracks present $\left\langle d_{s} d_{e}^{-1}\right\rangle$ greater than the median value of the data (0.37) while in the open ocean this is true for $45 \%$ of the drifter trajectories. At the same time, on-shelf tracks present a mean $\left\langle\theta_{u_{r}}\right\rangle$ of $17.32^{\circ}$ with a standard deviation of $10.93^{\circ}$ while in the open ocean the mean $\left\langle\theta_{u_{r}}\right\rangle$ is $-1.42^{\circ}$ and the standard deviation is $29.59^{\circ}$.

\subsubsection{The Effect of Coupling on the Stokes Drift}

The impact of ocean-wave coupling on the Stokes drift can be assessed comparing Lagrangian simulations using the same data for the ocean currents but different forcing for the Stokes drift, i.e., contrasting $U_{c t r} S_{c t r}$ against $U_{c t r} S_{c p l}$ and $U_{c p l} S_{c t r}$ against $U_{c p l} S_{c p l}$, respectively.

Table 5 reveals that ocean-wave coupling has, on average, a small (or negligible) impact on the wave-induced currents, with a difference in the average skill score between off- and on-shelf simulations of $\pm 1 \%$. This result is in line with our expectations, since formally the FOAM-AMM15 coupled system does not include any new ocean currents effect to the action density balance equation solved by the spectral wave model. 

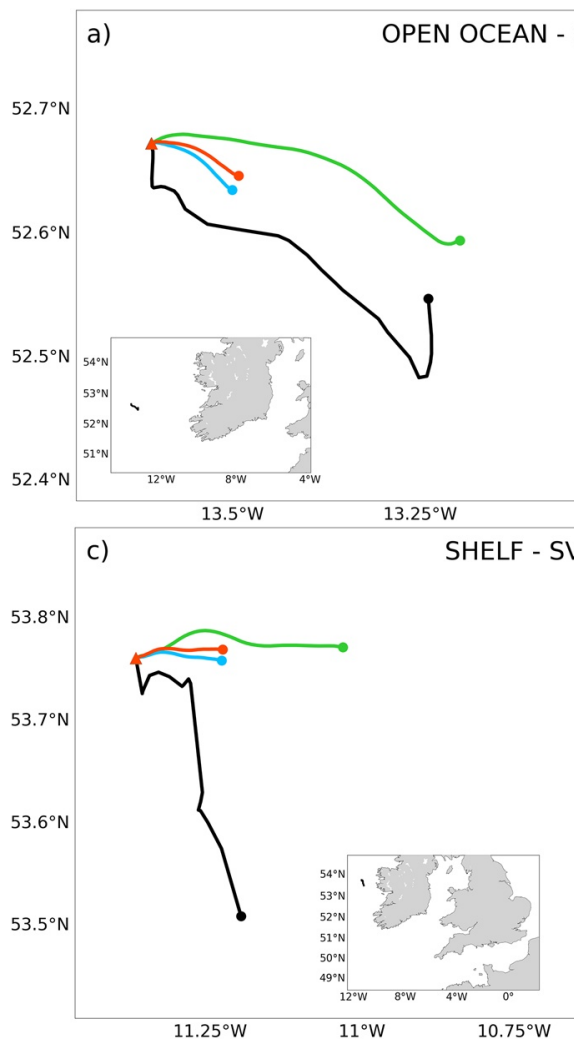

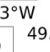

$49.4^{\circ} \mathrm{N}$

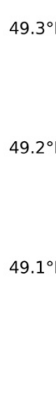

$49.2^{\circ} \mathrm{N}$

$49.1^{\circ} \mathrm{N}$

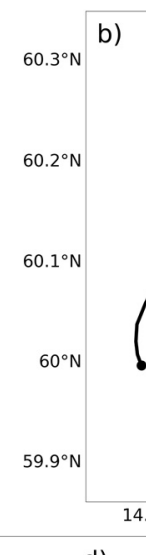

d)
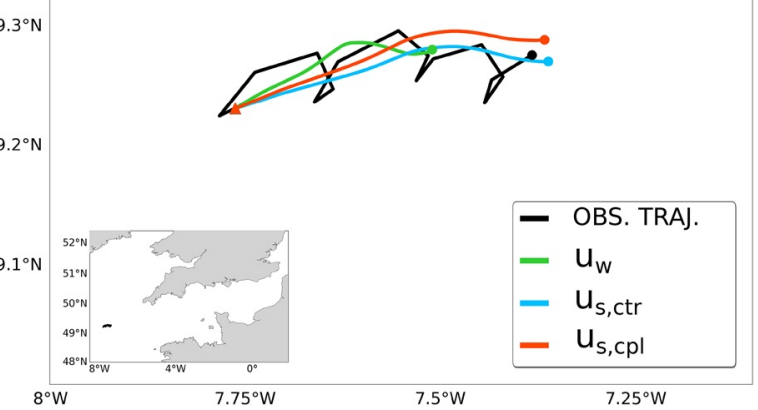

OPEN OCEAN - iSphere

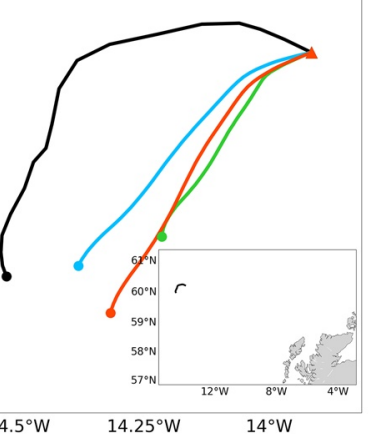

SHELF - iSphere

Figure 10. Examples of open ocean and on-shelf iSphere and Surface Velocity Program (SVP) drifter simulations obtained forcing the Lagrangian model only with wind leeway ( $\boldsymbol{u}_{w}$, green trajectories) or only with the Stokes drift from either the CTR $\left(\boldsymbol{u}_{s, c t r}\right.$, light-blue lines) or the CPL ( $\boldsymbol{u}_{s, c p l}$, red tracks) trial runs.

However, Figure 6 seems to indicate that the tracks simulated forcing the Lagrangian model with the CPL Stokes drift are consistently deflected in comparison to the ones using the Stokes drift from the uncoupled system, especially at the surface (compare light-blue against yellow lines and/or green against red lines).

The direction of the Stokes drift at the surface usually correlates relatively well with the wind direction, since it is more sensitive to the high-frequency part of the wave spectra (e.g., Tuomi et al., 2018; Webb \& Fox-Kemper, 2015). In order to investigate whether differences in the Stokes drift direction may be related to the wind direction, we conducted three additional Lagrangian experiments: in the first one virtual drifters where forced only with the wind leeway $\left(\boldsymbol{u}_{w}\right)$ while in the other two we applied only the Stokes drift forcing from either the CTR $\left(\boldsymbol{u}_{s, c t r}\right)$ or the CPL $\left(\boldsymbol{u}_{s, c p l}\right)$ trials, respectively.

Table 6

Mean Track-Averaged Veering $\left\langle\theta_{u_{s}}\right\rangle$ of Stokes Drift Vectors From CTR and CPL Trial Datasets with Respect to the Wind Leeway Direction

\begin{tabular}{|c|c|c|c|c|}
\hline \multirow[b]{2}{*}{ Drifter type } & \multirow[b]{2}{*}{ Region } & \multirow[b]{2}{*}{ Numb. of drifters } & \multicolumn{2}{|c|}{$\operatorname{Mean}\left\langle\theta_{u_{s}}\right\rangle\left[^{\circ}\right]$} \\
\hline & & & CTR & CPL \\
\hline \multirow[t]{2}{*}{ iSphere } & shelf \& shelf-break & 10 & 5.50 & 1.52 \\
\hline & open ocean & 21 & 5.46 & -3.50 \\
\hline \multirow[t]{2}{*}{ SVP } & shelf \& shelf-break & 2 & 6.19 & -0.80 \\
\hline & open ocean & 16 & 6.09 & -3.44 \\
\hline
\end{tabular}

Note. The veering is computed according to Kundu (1976).
Figure 10 shows some examples of the results from this last set of simulations. The virtual trajectories obtained forcing the Lagrangian model with the CPL Stokes drift are more closely aligned with the ones using only the wind leeway, suggesting that switching on the three wave feedbacks in the FOAM-AMM15 momentum balance equation may have a control also on the direction of the Stokes drift computed by the wave model.

In order to quantify this effect, Table 6 presents the mean track-averaged veering $\left\langle\theta_{u_{s}}\right\rangle$ of CTR and CPL Stokes drift vectors with respect to the wind leeway direction computed according to Kundu (1976). Results shows that the Stokes drift from the coupled run reduce the veering from the wind direction by more than $50 \%$ in comparison with the one of the Stokes drift from the uncoupled system, in agreement with observations (e.g., Clarke and Van Gorder [2018]). 
Table 7

Average Skill Score $\overline{S S}$ and Standard Deviation SD of iSphere and SVP Drifters on the Shelf and in the Open Ocean for the Following Five Lagrangian Experiments: CTR and CPL Simulations Used Ocean Currents and Stokes Drift From an Uncoupled and a Fully Coupled FOAM-AMM15 System, Respectively; the CSF Experiment Used Ocean and Wave Data From an Ocean-Wave Simulation Where Only the Coriolis-Stokes Wave Effect was Activated; the TOC Lagrangian Simulations Used Forcing Data Produced by the FOAM-AMM15 System Using Only the Wave-Dependent Momentum Flux; the WSR Experiments Forced the Lagrangian Model With Data From an Ocean-Wave Simulation Activating Only the Sea-State Dependent Sea Surface Roughness

\begin{tabular}{|c|c|c|c|c|c|c|c|}
\hline \multirow[b]{2}{*}{ Drifter type } & \multirow[b]{2}{*}{ Region } & \multirow{2}{*}{$\begin{array}{c}\text { Numb. of } \\
\text { drifters }\end{array}$} & \multicolumn{5}{|c|}{$\overline{s s} \pm \mathrm{SD}$} \\
\hline & & & CTR & CPL & CSF & TOC & WSR \\
\hline \multirow[t]{2}{*}{ iSphere } & shelf \& shelf-break & 7 & $0.74 \pm 0.08$ & $0.81 \pm 0.09$ & $0.79 \pm 0.09$ & $0.75 \pm 0.07$ & $0.80 \pm 0.09$ \\
\hline & open ocean & 16 & $0.54 \pm 0.22$ & $0.58 \pm 0.17$ & $0.58 \pm 0.19$ & $0.55 \pm 0.21$ & $0.57 \pm 0.18$ \\
\hline \multirow[t]{2}{*}{ SVP } & shelf \& shelf-break & 1 & 0.34 & 0.61 & 0.53 & 0.47 & 0.32 \\
\hline & open ocean & 13 & $0.42 \pm 0.25$ & $0.49 \pm 0.25$ & $0.47 \pm 0.24$ & $0.45 \pm 0.22$ & $0.45 \pm 0.22$ \\
\hline
\end{tabular}

Abbreviations: TOC, Tau ocean; WSR, wave sea surface roughness.

\subsection{The Relative Impact of Each Single Ocean-Wave Interaction}

The aim of this section is to quantify which one of the three wave-current interactions included in the FOAM-AMM15 coupled system has the larger impact on the accuracy of the solution for the surface dynamics.

Five different Lagrangian experiments are compared (see Table 7). Two of them forced the Lagrangian model with ocean and wave data from CTR and CPL trials. The other three experiments used forcing data from FOAM-AMM15 simulations where only one wave-current interaction was switched on: CSF used only the Coriolis-Stokes forcing, TOC only the wave-dependent water-side stress while WSR only the sea-state modulated sea surface roughness (see Section 2.2.2 for the details). In the case of open ocean iSpheres, the Lagrangian simulations were forced using also the wind leeway. Since CSF, TOC and WSR ocean-wave simulations covered only the storms occurred in January-February (i.e., Gertrude, Henry and Imogen), only 37 drifter trajectories were simulated in this set of Lagrangian experiments.

Numerical results presented in Table 7 indicate that the best skill score is obtained when the three wave-current interactions are considered. The Coriolis-Stokes forcing seems to be the dominant wave-current interaction for both iSphere $(0.64 \pm 0.20)$ and SVP $(0.48 \pm 0.23)$ drifters, in agreement with the results of the simplified wave-modified Ekman model of Section 3. In the case of iSpheres, the second most important wave effect seems to be the wave-dependent sea surface roughness $z_{0}(0.63 \pm 0.19)$ while for SVPs is the wave-dependent momentum flux $(0.46 \pm 0.22)$, especially on the shelf.

The visual inspection of the simulated trajectories may help to better understand the dynamical impact of each wave-current interaction. Figure 11 presents four examples of drifter tracks simulations from CTR (in light-blue), CPL (in red), CSF (in green), TOC (in yellow) and WSR (in violet) Lagrangian experiments representative of iSpheres and SVPs in open ocean and on-shelf conditions.

In the case of the on-shelf iSphere (see Figure 11a), the TOC trajectory is slightly faster than the CTR one, indicating that $\tau_{o c n}$ is generally larger than $\tau_{a t m}$ but to a small extent. At the same time, the WSR virtual drifter is significantly slower than the CTR: in the uncoupled simulation $H_{s}$ is underestimated (see Figure $8 \mathrm{~b}$ ), resulting in a smaller $z_{0}$, reduced vertical shear and consequently increased surface currents, in agreement with the findings of Carniel et al. (2009). The CPL and CSF trajectories are very similar, confirming the supremacy of the CSF.

Conversely, in the open ocean iSphere case (see Figure 11c) both TOC and WSR drifters are slower than the CTR one, indicating that $\tau_{o c n}<\tau_{a t m}$ and $z_{0}$ is larger when computed by the wave model, respectively. However, the CPL trajectory seems to be an hybrid between both CSF and WSR tracks, confirming the leading role of both wave effects in the open ocean as found in Table 7. 

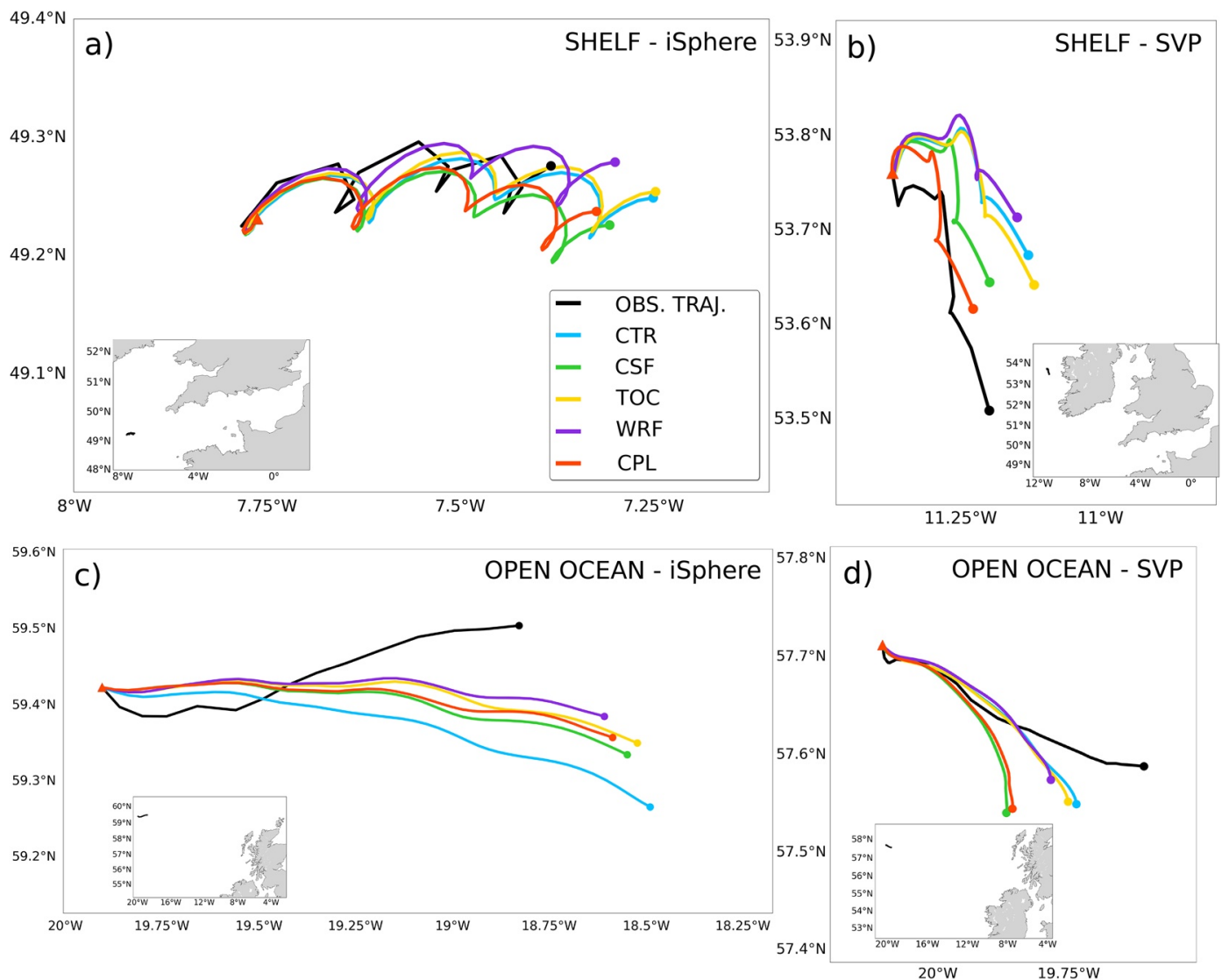

Figure 11. Simulated trajectories from CTR (in light-blue), CPL (in red), CSF (in green), TOC (in yellow) and WSR (in violet) Lagrangian experiments representative of open ocean and on-shelf iSphere and Surface Velocity Program (SVP) drifters.

SVP drifters seem to be affected by the same dynamics of surface drifting buoys, although with some differences. In the case of the on-shelf SVP drifter (see Figure 11b), the wave-modulated water-side stress $\tau_{o c n}$ seems to dominate the wave-dependent $z_{0}$ (CPL and TOC virtual drifters show very similar velocity) while for the open ocean SVP (see Figure 11d) the CPL drifter seems to follow a path very similar to the CSF one but with slightly slower speed as in the TOC simulation. As one can expect, SVPs simulations are less impacted by the sea-state modulated $z_{0}$, indicating that this wave-related process might be less important for the sub-surface circulations.

Numerical results show that the wave-dependent momentum flux might have quite an important impact on the accuracy of numerical SVP trajectories. The resolution of the vertical grid near the surface plays an important role in the propagation of the momentum from the atmosphere down into the water column (e.g., Carniel et al., 2009). If the model vertical grid is too coarse, the shear of the Ekman current might be overestimated, resulting in a too weak modeled sub-surface circulation. Assuming that AMM15 vertical discretization is lacking the required resolution near the surface could explain why SVP simulations have generally lower skill score $(<0.5)$. AMM15-ocean uses 51 s-levels with a constant thickness of $1 \mathrm{~m}$ for the uppermost grid cell in areas where the depth is larger than $50 \mathrm{~m}$ (Siddorn \& Furner, 2013). Research activities are ongoing for improving the vertical resolution of this model, taking into consideration also this aspect (Bruciaferri et al., 2021). However, the type of vertical discretization impacts the accuracy of a wide range of physical processes reproduced by an ocean model and the choice of the vertical grid is not an easy task and must be pursued very carefully (e.g., Bruciaferri et al., 2018, 2020; Siddorn \& Furner, 2013). 


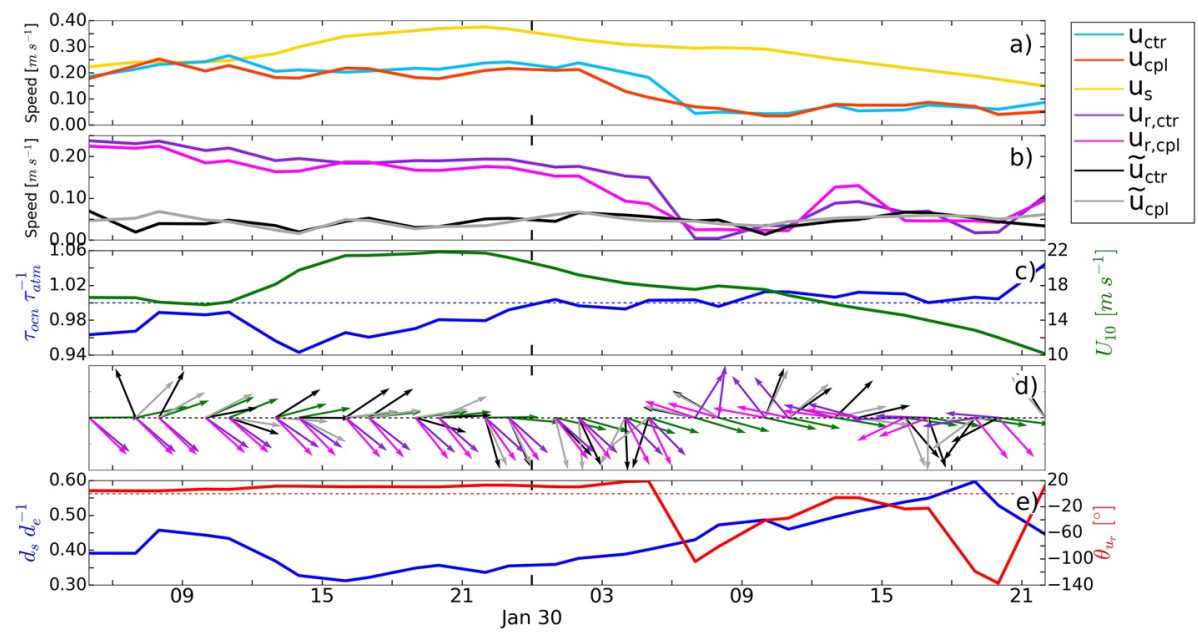

Figure 12. Diagnostics computed along the observed iSphere track shown in Figure 11c representing deep water conditions. Time-series of (a) CTR (light-blue) and CPL(red) ocean currents and Stokes drift (yellow) speed; (b) CTR and CPL $u_{t, c t r}$ (black) and $u_{t, c p l}$ (gray) tidal currents and $u_{r, c t r}$ (violet) and $u_{r, c p l}$ (magenta) residual currents; (c) 3 hourly ECMWF wind speed (green) and $\tau_{o c n} \tau_{a t m}^{-1}$ ratio (blue); (d) wind (green), high frequency $\tilde{u}_{c t r}$ (black) and $\tilde{u}_{c p l}$ (gray) and residual $u_{r, c t r}$ (violet) and $u_{r, c p l}$ (magenta) vector directions; veering $\theta_{u_{r}}$ of $u_{r, c p l}$ with respect to $u_{r, c t r}$ (red) and $d_{s} d_{e}^{-1}$ ratio (blue).

\subsection{Physical Processes Driving Surface Drifters During Storms}

The aim of this Section is to obtain further insights about some of the details underpinning the physical mechanisms driving the transport of open ocean and on-shelf drifters during the storms. We explore and discuss the time-series of a number of diagnostics computed along the observed track of a couple of iSpheres chosen to represent open ocean and on-shelf conditions. The analysis is conducted only for surface drifters since the results of Section 4.1 indicated that SVPs simulation might be affected by inaccuracies not related with ocean-wave coupling.

The open ocean case considers the iSphere trajectory presented in Figure 11c. During the storm, the drifter is primarily transported by the Stokes drift, as showed by the time-series of the along-track ocean and wave-induced currents speed from CTR and CPL trials presented in Figure 12a. In addition, Figure 12b reveals that residual currents are the second most important forcing while the high frequency flow $\tilde{\boldsymbol{u}}$ represents the minor transport process.

Time-series of along-track CTR and CPL residual currents speed (Figure 12b, violet and magenta lines respectively) seems to correlate quite well with the along-track wind speed time-series (Figure 12c, green line), indicating that wind-driven currents might represent the dominant component of the residual circulation. The time evolution of the differences between $u_{r, c t r}$ and $u_{r, c p l}$ signals and the time-series of $\tau_{o c n} \tau_{a t m}^{-1}$ ratio (Figure $12 \mathrm{c}$, blue line) seem to confirm this: from January 29, $\approx 10: 00 \mathrm{am}$ to January 30, $\approx 6: 00 \mathrm{am}$ the drifter track is affected by high wind speeds $\left(U_{10}>16 \mathrm{~m} \mathrm{~s}^{-1}\right), \tau_{\text {ocn }}<\tau_{\text {atm }}$ and consequently $u_{r, c t r}>u_{r, c p l}$. After, the wind speed decreases to values below $12 \mathrm{~m} \mathrm{~s}^{-1}, \tau_{\text {ocn }} \approx \tau_{a t m}$ and the differences between $u_{r, c t r}$ and $u_{r, c p l}$ seem less related to the wind dynamics, suggesting the weakening of the wind-driven component of the residual circulation.

Figure 12d presents time-series of wind, residual and high frequency currents vector directions. During the high-wind period, residual vectors are consistently to the right of the wind direction (see violet and magenta vectors with respect to green arrows), as from the classical Ekman theory for the wind-driven circulation. In addition, CPL residual currents present a consistent clockwise additional veering of $5-15^{\circ}$ with respect to CTR currents (see red line of Figure 12e), in agreement with the storm modified Ekman model of Section 3. When the wind decreases, the wind-driven circulation weakens, as shown by the high variability of the veering $\theta_{u_{r}}$ (see violet and magenta vectors in Figure 12d and red line in Figure 12e). In the open ocean, the high frequency flow $\tilde{\boldsymbol{u}}$ includes both tidal and inertial currents, as shown in Figure 8 (note that the location of the open ocean drifter trajectory analyzed in this section is very close to the S1 station of Figure 8). 


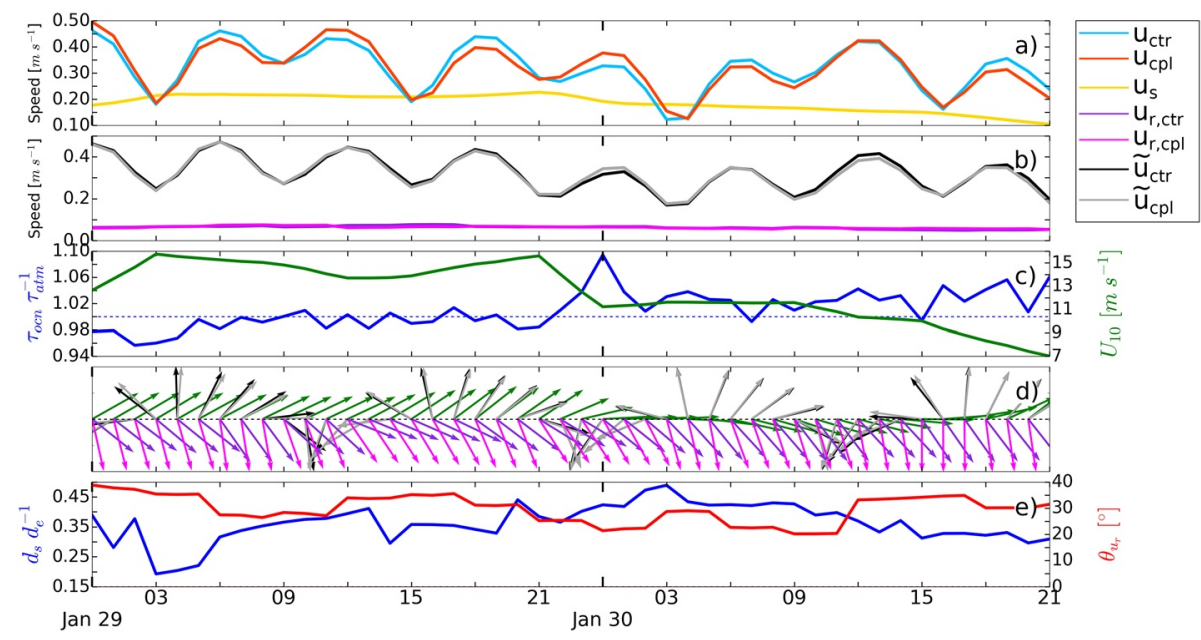

Figure 13. Diagnostics computed along the observed iSphere track shown in Figure 11a representing on-shelf conditions. Time-series of (a) CTR (light-blue) and CPL(red) ocean currents and Stokes drift (yellow) speed; (b) CTR and CPL $u_{t, c t r}$ (black) and $u_{t, c p l}$ (gray) tidal currents and $u_{r, c t r}$ (violet) and $u_{r, c p l}$ (magenta) residual currents; (c) 3 hourly ECMWF wind speed (green) and $\tau_{\text {ocn }} \tau_{a t m}^{-1}$ ratio (blue); (d) wind (green), high frequency $\tilde{u}_{c t r}$ (black) and $\tilde{u}_{c p l}$ (gray) and residual $u_{r, c t r}$ (violet) and $u_{r, c p l}$ (magenta) vector directions; veering $\theta_{u_{r}}$ of $u_{r, c p l}$ with respect to $u_{r, c t r}$ (red) and $d_{s} d_{e}^{-1}$ ratio (blue).

Therefore, differences in direction between CTR and CPL $\tilde{\boldsymbol{u}}$ (gray and black vectors in Figure 12d) are probably due to the effects of coupling on the mesoscale dynamics. During the high-wind phase the ratio $d_{s} d_{e}^{-1}$ oscillates around 0.35 while in the low-wind phase grows up to 0.60 (see blue line in Figure 12e): in this case the diagnostic $d_{s} d_{e}^{-1}$ seems to be controlled more by the dynamics of the wind-driven circulation (i.e., the Ekman scale) than the CSF (i.e., the Stokes depth).

For the on-shelf scenario we chose the iSphere track presented in Figure 11a. On the shelf, the high frequency flow $\tilde{\boldsymbol{u}}$ includes mainly tidal currents (see Figure 8). Figures 13a and 13b show that the on-shelf drifter is prevalently transported by tidal currents while the Stokes drift and the residual flow represent the second and third forcing, respectively. High wind speeds $\left(U_{10}>13 \mathrm{~m} \mathrm{~s}^{-1}\right)$ affect the on-shelf track on January 29 from $\approx 3: 00$ am to $\approx 9: 00 \mathrm{pm}$, while wind speeds drop to less than $\approx 10 \mathrm{~m} \mathrm{~s}^{-1}$ during the second part of the trajectory (see green line in Figure 13c). Differences between CPL and CTR total currents speed time-series (Figure 13a, red and light-blue lines, respectively) show a periodic pattern which suggests an interplay between tides and wave feedbacks on the ocean currents. Figure $13 \mathrm{~d}$ reveals the details of this interaction: CPL residual currents present an additional clockwise veering relative to the CTR field due to the Coriolis-Stokes acceleration which affects the vector sum with the tidal circulation, with the final result of modulating the magnitude of total currents.

The additional veering $\theta_{u_{r}}$ of CPL residual currents is consistently positive along the entire track, with values around $20-30^{\circ}$ (see red line in Figure 13e): during the low-wind phase the CSF is probably acting on wind-driven inertial oscillations triggered by the wind drop at the end of January 29. The time-series of $d_{s} d_{e}^{-1}$ (blue line of Figure 13e) shows slightly larger values during the low-wind wave-decaying phase.

\section{Discussion}

The results of Section 4 indicated that improvements in the average skill score of iSphere and SVP Lagrangian simulations due to wave feedbacks on the ocean currents are larger on the shelf than in the open ocean. Our analysis indicates that several physical mechanism related to the contrasting dynamical regime of deep ocean and shallow marine environments might contribute to this result (see for example Bruciaferri (2020) and references therein for a review of physical and numerical challenges characterizing shelf seas dynamics). 
For example, Figures 7 and 9a indicate that, during our storms, deep ocean and shelf areas might be affected by wind-waves at different stages of wave-growth: in the open ocean, we might be in the presence of younger growing waves where part of the atmospheric stress is transferred to the rapidly developing wavefield reducing the water-side momentum flux while in shelf areas more developed decaying waves may tend to release momentum into the ocean increasing the water-side stress.

In addition, Figure 9b clearly shows that in the presence of severe sea-states the $H_{s}$ calculated by the wave model is consistently larger than the one estimated from the wind speed, resulting always in a larger $z_{0}$ both off- and on-shelf.

Combining the findings of Figures 9a-9c suggest that off-shelf the sea state controlled $\tau_{\text {ocn }}$ and $z_{0}$ might cooperate to reduce the strength of the ocean currents $\boldsymbol{u}$ while on the shelf they might counteract each other resulting in a $u_{c p l}$ more similar to $u_{c t r}$. The same mechanism seem to be confirmed by the simulations of Section 4.3. In the case of the on-shelf drifter (Figure 11a), the virtual drifter is slower in the CPL simulation than in the CTR one, indicating that the sea-state controlled $z_{0}$ prevails on the wave-dependent stress $\tau_{\text {ocn }}$. Conversely, in the open ocean case (Figure 11c), both $\tau_{\text {ocn }}$ and $z_{0}$ wave feedbacks cooperate to reduce the magnitude of the surface currents. Similarly, the analysis of Figure 13 shows that while $\tau_{\text {ocn }} \tau_{\text {atm }}^{-1}$ time-series correlates quite well with the wind speed signal - i.e., $\tau_{\text {ocn }} \leq \tau_{\text {atm }}\left(\tau_{\text {ocn }}>\tau_{\text {atm }}\right)$ during the high-wind (lowwind) phase - CTR and CPL residual currents present very small differences in magnitude during the entire track. This is probably an indication of the competition between the wave-dependent $\tau_{\text {ocn }}$ and $z_{0}$, especially during the low-wind phase.

The results of Figure 9d seem to indicate that the findings of the simplified storm-modified Ekman model presented in Section 3 might apply also to our more realistic scenario: in shallow areas, the Coriolis-Stokes forcing appears to affect a larger portion of the Ekman depth with CPL residual currents presenting a consistent positive veering with respect to the CTR residual flow; conversely, in the open ocean $d_{s}$ tend to be shallower and $\left\langle\theta_{u_{r}}\right\rangle$ shows larger variability, suggesting a weaker impact of the CSF term.

Finally, the analysis presented in Figure 8 and Section 4.4 showed that the three wave feedbacks included in the FOAM-AMM15 coupled system mainly impact the wind-driven meso-scale circulation while it has practically not direct effect on the tidal dynamics, especially on the shelf. However, Figure 13 revealed also that net on-shelf circulation is importantly modulated by the interaction between the strong tidal flow and the wave-modified wind-induced currents.

Figure 14 summarizes the main mechanisms involving wind-driven circulation, tidal currents and wave feedbacks on the ocean momentum budget in the open ocean (a) and on the shelf (b) during the storms considered in our study.

In general, the open ocean is impacted by younger shorter waves (see Figure 14a). Two main consequences follow from this: (i) part of the atmospheric stress is extracted by the rapidly growing wavefield, reducing on average the momentum flux into the ocean $\tau_{\text {ocn }}$; (ii) the importance of the Stokes' depth scale $d_{s}$ with respect to the Ekman depth $d_{e}$ is generally decreased, making the Coriolis-Stokes veering $\theta_{u_{r}}$ less pronounced than on the shelf. When the reduced $\tau_{\text {ocn }}$ combines with the constantly larger $z_{0}$, the result is that both wave effects generally act in synergy to slow down ocean currents. In addition, tidal currents are also weak off-shelf, making the interactions between waves, tides and residual circulation less important as well.

On the shelf (see Figure 14b), wind-waves are generally more mature than in the open ocean, resulting in (i) net outflux of momentum from waves into the ocean (i.e., $\tau_{\text {ocn }}>\tau_{\boldsymbol{a t m}}$, and (ii) relatively larger $d_{s} d_{e}^{-1}$ ratio with increased and more consistent Coriolis-Stokes veering $\theta_{u_{r}}$. In this case, the increased momentum flux into the ocean $\tau_{\text {ocn }}$ and the larger roughness length $z_{0}$ seem to compete one against another, resulting in almost vanishing their mutual impacts on the ocean currents strength. Shallow areas are affected also by very strong tidal currents, making the interactions between waves, tides and residual circulation a leading order process. 

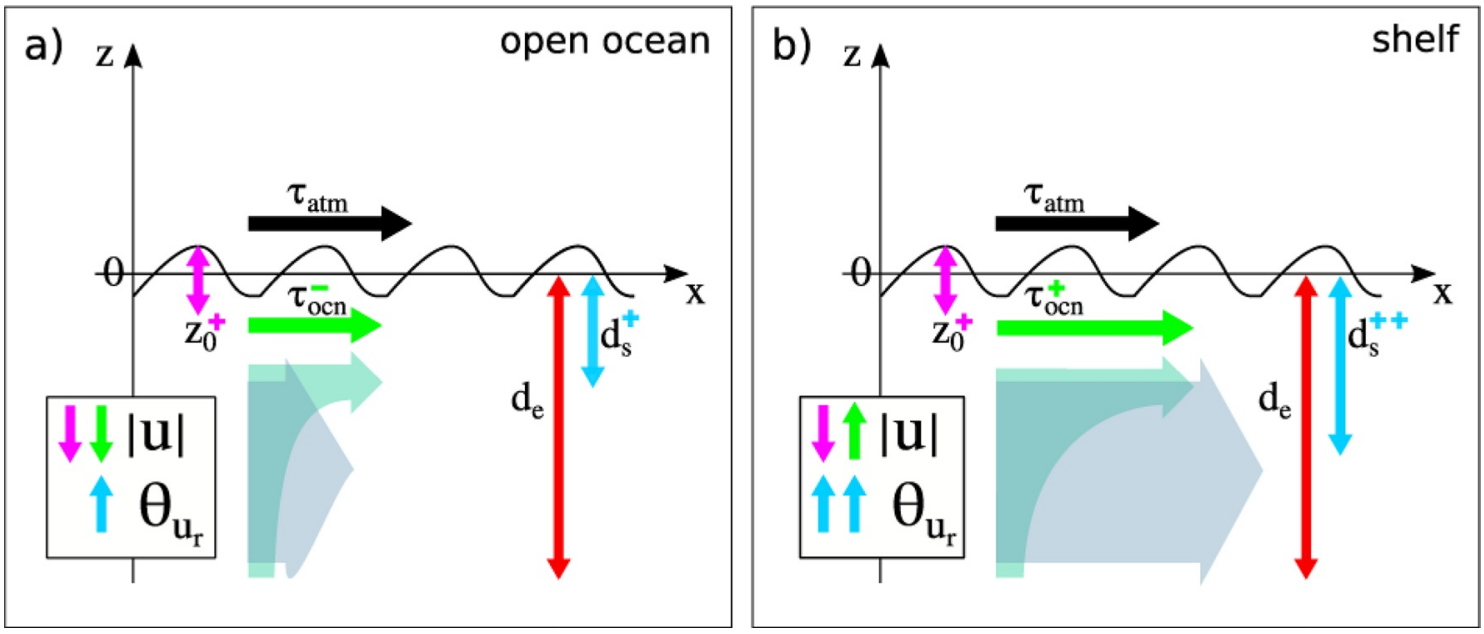

Figure 14. Sketch describing the main mechanisms relating wind-driven circulation, tidal currents and wave feedbacks on the ocean momentum budget in the open ocean (a) and on the shelf (b). The gray-blue thick arrows represent tides, while the green-blue curved arrows describe sheared wind-driven currents. Wave feedbacks are indicated with a plus or minus, while their final effect on the ocean currents (magnitude $|\boldsymbol{u}|$ or direction $\theta_{u_{r}}$ ) is explained by the vertical arrows in the boxes. Also, $z_{0}$ is the roughness length, $d_{s}$ the Stokes' depth, $d_{e}$ the Ekman scale while $\tau_{a t m}$ and $\tau_{\text {ocn }}$ are the air- and water-side stresses, respectively. See the text for a detail description of the processes.

\section{Conclusions}

In this study, we assess and analyze the impact of including three wave-dependent processes in the momentum equation solved by the ocean model of the Met Office ocean-wave forecasting system of the NWS. Our focus is on the accuracy of the simulated upper ocean circulation in the presence of severe sea-states. The analysis is conducted using upper ocean velocities produced by various versions of the NWS forecasting system differing only in the level of ocean-wave coupling to simulate the trajectories of a number of drifters affected by four Atlantic storms occurred in winter 2016.

Sensitivity experiments showed that, regardless the level of coupling, including the wind drag velocity in the Lagrangian transport equation allows the improvement of numerical tracks' accuracy in the open ocean while significantly degrades the results in shallow areas. Assessment against independent observations indicated that one reason that improvements are not evident on the shelf might be the inaccuracies affecting wind model data in shelf and coastal areas, in agreement with other studies (e.g., Christakos et al., 2020).

Lagrangian experiments to assess the benefit of ocean-wave coupling showed that, in the presence of extreme events, using forcing data from a fully coupled system allows to improve the skill of the numerical drifter trajectories by $\approx 4 \%$. In addition, results showed that improvements are comparable for both iSphere and SVP drifters, suggesting that, during storms, the three wave-related processes included in the NWS coupled system might extend below the surface and impact a larger part of the upper ocean.

Ocean-wave coupling primarily impacts ocean currents, improving the accuracy of the predicted surface dynamics by $\approx 4 \%$ in the open ocean (from $0.50 \pm 0.23$ to $0.54 \pm 0.24$ ) and $\approx 8 \%$ on the shelf (from $0.71 \pm 0.14$ to $0.79 \pm 0.09$ ). Our analysis showed that this is probably a consequence of the contrasting dynamical regimes characterizing deep and shallow marine environments, with stronger tidal currents, a more vigorous wind-driven circulation and a more pronounced Coriolis-Stokes veering on the shelf than in the open ocean.

Numerical results indicated that the CSF is the dominant wave-current interaction during storm events, both off- and on-shelf. In addition, we found that in the case of surface iSpheres, the second most important wave effect is the wave-dependent sea surface roughness while for $15 \mathrm{~m}$ drogued SVP drifters is the wave modified water-side stress.

The impact of ocean-wave coupling on the Stokes drift seems to be not relevant in terms of skill score improvements. However, a more in depth analysis showed that the Stokes drift from a fully coupled system 
is deflected to be more aligned with the wind direction in comparison with the one from the uncoupled system, in agreement with observations (e.g., Clarke \& Van Gorder, 2018).

All our ocean simulations parameterized the input of turbulence at the surface due to wave-breaking according to Craig and Banner (1994), with no sea-state feedback. Similarly, wave effects on the bottom friction were not considered. However, our experiments showed that, during extreme events, the sea surface roughness simulated by the coupled system is consistently enhanced with respect to the one parameterized by the stand-alone ocean model. This might indicate that including the input of wave-induced turbulence in the coupling strategy (both at the surface and the bottom, e.g., Staneva, Wahle, Günther, \& Stanev, 2016) may help to further improve the accuracy of the simulated upper ocean dynamics, especially in shallow areas. Wu et al. (2019) highlighted the impact of using both the CSF and the mass and tracers advection due to the Stokes drift. The latter effect is not included in the current implementation of the Met Office NWS ocean-wave coupled forecasting system. Given the importance of the CSF found in our study, it seems reasonable to explore in the future also the impact of this other Stokes drift related process on the surface circulation of the NWS.

In the case of SVPs we found that, independently from ocean-wave coupling, simulated drifter trajectories are generally slower than the observed ones. This might be due to the inability of the ocean-wave modelling system to properly represent some storm-related physical processes which may promote enhanced transport (e.g., drifters surfing large waves). Alternatively, slower wind-induced currents below the surface could also indicate that the ocean model is overestimating the vertical shear of Ekman circulation, for example due to a vertical grid which may discretize the upper ocean with not enough details.

One possible limitation of this study is the number of observations: while with 49 satellite-tracked trajectories we are able to cover quite extensively the open ocean, drifters on the shelf are more scarce, especially in the North Sea.

This study shows that coupled circulation-wave models may be fundamental for improving our ability of predicting the transport and fate of particles and objects floating on the sea surface, with important practical implications for example for search and rescue activities or oil spill and plastic dispersal monitoring and control operations.

\section{Appendix A: Algorithm to Identify Storm-Affected Trajectories}

In order to identify the drifters trajectories which were affected by the four storms considered in this study, drifter observations from the CMEMS NWS in-situ product (Wehde et al., 2021) data set were pre-processed with the following algorithm.

For each drifter trajectories:

1. Consider the time window when each storm was recorded as active in winter 2016 on the NWS (Gertrude: January 29-30; Henry: February 1-2; Imogen: February 8; Jake: March 1-4);

2. Extend the identified time-window by adding the day after and before its limits;

3. Interpolate AMM15-wave $H_{s}$ fields along the observed drifter trajectory during the identified time-window.

The result is a time-series of the $H_{s}$ along each drifter trajectory during each storm. Then, for each $H_{s}$ time-series:

1. Compute the peak as the record of the time-series where $H_{s}>H_{s 99}$ (Masselink et al., 2016), where $H_{s 99}$ is the $1 \%$ exceedance $H_{s}$ (i.e., the $H_{s}$ with a value which is exceeded in the time-series only $1 \%$ of the time);

2. Discard all the time-series presenting a $H_{s}$ peak less than $6 \mathrm{~m}$;

3. Compute the beginning (end) of the along-drifter storm as the record of the $H_{s}$ time-series occurred before (after) the peak of the storm which is nearest in time to the occurrence of the peak and with $H_{s}<H_{s 30}$ (i.e., the $H_{s}$ with a value which is exceeded in the timeseries $70 \%$ of the time).

As an example, Figure A1 presents the $H_{s}$ time-series along the trajectories of those drifters identified by the algorithm for storm Henry. 


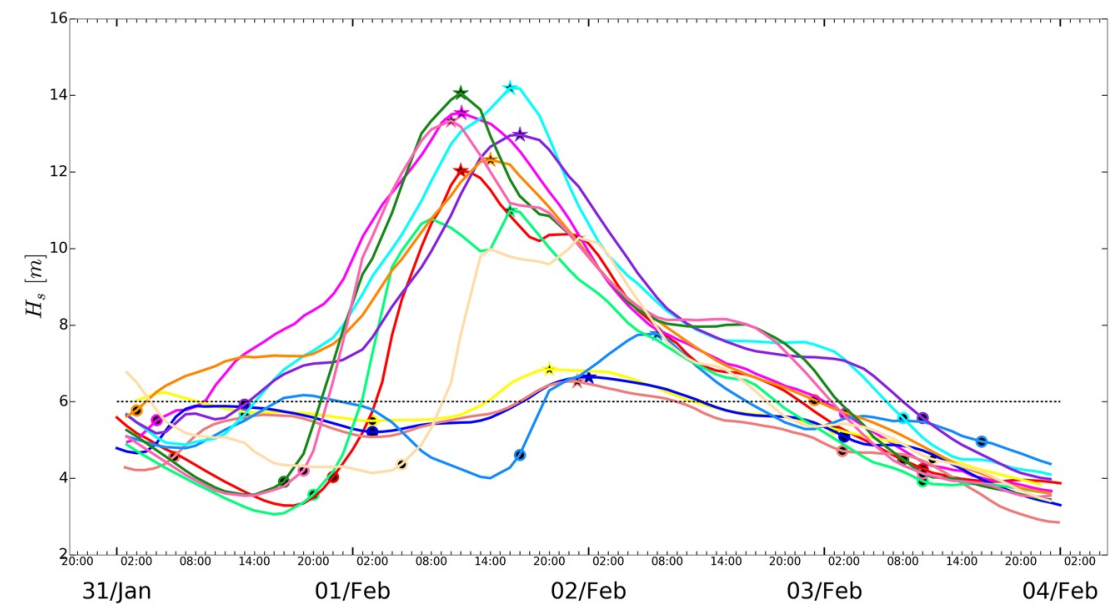

Figure A1. Time-series of along-track $H_{s}$ for those drifters identified by our algorithm during storm Henry.

\section{Data Availability Statement}

All the data used in this study are freely accessible from the European Copernicus Marine Environment Monitoring Service (CMEMS) portal (https://marine.copernicus.eu/): 1. AMM15 ocean currents data are archived in the CMEMS ocean product named NORTHWESTSHELF_ANALYSIS_FORECAST_ PHY_004_013 (Tonani et al., 2021); 2. AMM15 wave data are archived in the CMEMS ocean product named NORTHWESTSHELF_ANALYSIS_FORECAST_PHY_004_014 (Saulter, 2021).; 3. Drifters observations data are archived in the CMEMS ocean product named INSITU_NWS_NRT_OBSERVATIONS_013_036 (Wehde et al., 2021). The Lagrangian model code used in this study is described in Dagestad et al. (2018); Dagestad and Röhrs (2019).

Acknowledgments

The authors are grateful to the valuable comments and suggestions of the two anonymous reviewers which have greatly contributed to improving the manuscript. Funding support from the EU-Copernicus Marine Environment Monitoring Service and the UK Ministry of Defence is gratefully acknowledged.

\section{References}

Abascal, A. J., Castanedo, S., Fernández, V., \& Medina, R. (2012). Backtracking drifting objects using surface currents from high-frequency (HF) radar technology. Ocean Dynamics, 62(7), 1073-1089. https://doi.org/10.1007/s10236-012-0546-4

Amemou, H., Koné, V., Aman, A., \& Lett, C. (2020). Assessment of a Lagrangian model using trajectories of oceanographic drifters and fishing devices in the Tropical Atlantic Ocean. Progress in Oceanography, 188, 102. https://doi.org/10.1016/j.pocean.2020.102426

Ardhuin, F., Marié, L., Rascle, N., Forget, P., \& Roland, A. (2009). Observation and estimation of Lagrangian, stokes, and Eulerian currents induced by wind and waves at the sea surface. Journal of Physical Oceanography, 39(11), 2820-2838. https://doi. org/10.1175/2009JPO4169.1

Ardhuin, F., Rogers, E., Babanin, A. V., Filipot, J.-F., Magne, R., Roland, A., et al. (2010). Semiempirical dissipation source functions for ocean waves. Part I: Definition, calibration, and validation. Journal of Physical Oceanography, 40(9), 1917-1941. https://doi. org/10.1175/2010JPO4324.1

Barron, C. N., Smedstad, L. F., Dastugue, J. M., \& Smedstad, O. M. (2007). Evaluation of ocean models using observed and simulated drifter trajectories: Impact of sea surface height on synthetic profiles for data assimilation. Journal of Geophysical Research, 112(C7), C07. https://doi.org/10.1029/2006JC003982

Bidlot, J.-R., Li, J.-G., Wittmann, P., Faucher, M., Chen, H., Lefevre, J.-M., et al. (2007). Inter-comparison of operational wave forecasting systems. In 10th International workshop on wave hindcasting and forecasting and coastal hazard symposium, North Shore. Oahu, Hawaii.

Breivik, Ø., \& Allen, A. A. (2008). An operational search and rescue model for the Norwegian Sea and the North Sea. Journal of Marine Systems, 69(1-2), 99-113. https://doi.org/10.1016/j.jmarsys.2007.02.010

Breivik, Ø., Allen, A. A., Maisondieu, C., \& Olagnon, M. (2013). Advances in search and rescue at sea. Ocean Dynamics, 63(1), 83-88. https://doi.org/10.1007/s10236-012-0581-1

Breivik, Ø., Bidlot, J. -R., \& Janssen, P. A. (2016). A Stokes drift approximation based on the Phillips spectrum. Ocean Modelling, 100, 49-56. https://doi.org/10.1016/j.ocemod.2016.01.005

Breivik, Ø., \& Christensen, K. H. (2020). A combined stokes drift profile under swell and wind sea. Journal of Physical Oceanography, 50(10), 2819-2833. https://doi.org/10.1175/JPO-D-20-0087.1

Breivik, Ø., Janssen, P. A. E. M., \& Bidlot, J.-R. (2014). Approximate stokes drift profiles in deep water. Journal of Physical Oceanography, 44(9), 2433-2445. https://doi.org/10.1175/JPO-D-14-0020.1

Breivik, Ø., Mogensen, K., Bidlot, J.-R., Balmaseda, M. A., \& Janssen, P. A. E. M. (2015). Surface wave effects in the NEMO ocean model: Forced and coupled experiments. Journal of Geophysical Research: Oceans, 120, 2973-2992. https://doi.org/10.1002/2014JC010565

Bruciaferri, D. (2020). Advanced methods for numerical modelling of regional seas. Phd dissertation, University of Plymouth. Retrieved from http://hdl.handle.net/10026.1/15809 
Bruciaferri, D., Harle, J., Wise, A., O'Dea, E., \& Polton, J. (2021). The impact of the vertical discretization scheme on the accuracy of a model of the European north-west shelf. Vienna, Austria. European Geosciences Union General Assembly 2021. https://doi.org/10.5194/ egusphere-egu21-415

Bruciaferri, D., Shapiro, G., Stanichny, S., Zatsepin, A., Ezer, T., Wobus, F., et al. (2020). The development of a 3D computational mesh to improve the representation of dynamic processes: The Black Sea test case. Ocean Modelling, 146, 101. https://doi.org/10.1016/j. ocemod.2019.101534

Bruciaferri, D., Shapiro, G. I., \& Wobus, F. (2018). A multi-envelope vertical coordinate system for numerical ocean modelling. Ocean Dynamics, 68(10), 1239-1258. https://doi.org/10.1007/s10236-018-1189-x

Callies, U., Groll, N., Horstmann, J., Kapitza, H., Klein, H., Maßmann, S., \& Schwichtenberg, F. (2017). Surface drifters in the German Bight: Model validation considering windage and Stokes drift. Ocean Science, 13(5), 799-827. https://doi.org/10.5194/os-13-799-2017

Carniel, S., Warner, J. C., Chiggiato, J., \& Sclavo, M. (2009). Investigating the impact of surface wave breaking on modeling the trajectories of drifters in the northern Adriatic Sea during a wind-storm event. Ocean Modelling, 30(2-3), 225-239. https://doi.org/10.1016/j. ocemod.2009.07.001

Christakos, K., Furevik, B. R., Aarnes, O. J., Breivik, Ø., Tuomi, L., \& Byrkjedal, Ø. (2020). The importance of wind forcing in fjord wave modelling. Ocean Dynamics, 70(1), 57-75. https://doi.org/10.1007/s10236-019-01323-w

Christensen, K., Breivik, Ø., Dagestad, K. -F., Röhrs, J., \& Ward, B. (2018). Short-term predictions of oceanic drift. Oceanography, 31(3), 59-67. https://doi.org/10.5670/oceanog.2018.310

Clarke, A. J., \& Van Gorder, S. (2018). The relationship of near-surface flow, stokes drift and the wind stress. Journal of Geophysical Research: Oceans, 123, 4680-4692. https://doi.org/10.1029/2018JC014102

Clementi, E., Oddo, P., Drudi, M., Pinardi, N., Korres, G., \& Grandi, A. (2017). Coupling hydrodynamic and wave models: First step and sensitivity experiments in the Mediterranean Sea. Ocean Dynamics, 67(10), 1293-1312. https://doi.org/10.1007/s10236-017-1087-7

Coleman, G. N., Ferziger, J. H., \& Spalart, P. R. (1990). A numerical study of the turbulent Ekman layer. Journal of Fluid Mechanics, 213, 313. https://doi.org/10.1017/S0022112090002348

Craig, P. D., \& Banner, M. L. (1994). Modeling wave-enhanced turbulence in the ocean surface layer. Journal of Physical Oceanography, 24, 2546-2559. https://doi.org/10.1175/1520-0485(1994)024<2546:MWETIT>2.0.CO;2

Csanady, G. T., \& Gibson, M. (2001). Air-sea interaction: Laws and mechanisms. Cambridge University Press. https://doi.org/10.1017/ CBO9781139164672

Cucco, A., Sinerchia, M., Ribotti, A., Olita, A., Fazioli, L., Perilli, A., et al. (2012). A high-resolution real-time forecasting system for predicting the fate of oil spills in the Strait of Bonifacio (western Mediterranean Sea). Marine Pollution Bulletin, 64(6), 1186-1200. https:// doi.org/10.1016/j.marpolbul.2012.03.019

Cushman-Roisin, B., \& Beckers, J.-M. (2011). Introduction to geophysical fluid dynamics - physical and numerical aspects (2nd ed., p. 875).

Dagestad, K.-F., \& Röhrs, J. (2019). Prediction of ocean surface trajectories using satellite derived vs. modeled ocean currents. Remote Sensing of Environment, 223, 130-142. https://doi.org/10.1016/j.rse.2019.01.001

Dagestad, K.-F., Röhrs, J., Breivik, Ø., \& Ådlandsvik, B. (2018). OpenDrift v1.0: A generic framework for trajectory modelling. Geoscientific Model Development, 11(4), 1405-1420. https://doi.org/10.5194/gmd-11-1405-2018

Davies, A. M., \& Lawrence, J. (1995). Modeling the effect of wave-current interaction on the three-dimensional wind-driven circulation of the eastern Irish Sea. Journal of Physical Oceanography, 25(1), 29-45. https://doi.org/10.1175/1520-0485(1995)025<0029:MTEOWI>2.0.CO;2

DeDominicis, M., Bruciaferri, D., Gerin, R., Pinardi, N., Poulain, P. M., Garreau, P., et al. (2016). A multi-model assessment of the impact of currents, waves and wind in modelling surface drifters and oil spill. Deep-Sea Research Part II: Topical Studies in Oceanography. 21-38. https://doi.org/10.1016/j.dsr2.2016.04.002

DeDominicis, M., Falchetti, S., Trotta, F., Pinardi, N., Giacomelli, L., Napolitano, E., et al. (2014). A relocatable ocean model in support of environmental emergencies - The Costa Concordia emergency case. Ocean Dynamics, 64(5), 667-668. https://doi.org/10.1007/ s10236-014-0705-X

DeDominicis, M., Pinardi, N., Zodiatis, G., \& Lardner, R. (2013). MEDSLIK-II, A Lagrangian marine surface oil spill model for short-term forecasting - Part 1: Theory. Geoscientific Model Development, 6, 1851-1869. https://doi.org/10.5194/gmd-6-1851-2013

Dohan, K., \& Maximenko, N. (2010). Monitoring Ocean Currents with Satellite Sensors. Oceanography, 23(4), 94-103. https://doi. org/10.5670/oceanog.2010.08

Ekman, V. W. (1905). On the influence of the Earth's rotation on ocean-currents. Arkiv för Matematik, Astronomi och Fysik, 2 , 1-52.

Fenton, J., \& McKee, W. (1990). On calculating the lengths of water waves. Coastal Engineering, 14(6), 499-513. https://doi. org/10.1016/0378-3839(90)90032-R

Gemmrich, J. R., \& Farmer, D. M. (1999). Near-surface turbulence and thermal structure in a wind-driven sea. Journal of Physical Oceanography, 29, 480-499. https://doi.org/10.1175/1520-0485(1999)029<0480:NSTATS $>2.0 . C O ; 2$

Gerbi, G. P., Trowbridge, J. H., Terray, E. A., Plueddemann, A. J., \& Kukulka, T. (2009). Observations of turbulence in the ocean surface boundary layer: Energetics and transport. Journal of Physical Oceanography, 39(5), 1077-1096. https://doi.org/10.1175/2008JPO4044.1

Graham, J. A., O'Dea, E., Holt, J., Polton, J., Hewitt, H. T., Furner, R., et al. (2018). AMM15: A new high-resolution NEMO configuration for operational simulation of the European north-west shelf. Geoscientific Model Development, 11(2), 681-696. https://doi.org/10.5194/ gmd-11-681-2018

Graham, J. A., Rosser, J. P., O'Dea, E., \& Hewitt, H. T. (2018). Resolving shelf break exchange around the European Northwest Shelf. Geophysical Research Letters, 45, 12386-12395. https://doi.org/10.1029/2018GL079399

Hasselmann, K. (1970). Wave-driven inertial oscillations. Geophysical Fluid Dynamics, 1(3-4), 463-502. https://doi. org/10.1080/03091927009365783

Hasselmann, S., Hasselmann, K., Allender, J. H., \& Barnett, T. P. (1985). Computations and parameterizations of the nonlinear energy transfer in a gravity-wave specturm. Part II: Parameterizations of the nonlinear energy transfer for application in wave models. Journal of Physical Oceanography, 15, 1378-1391. https://doi.org/10.1175/1520-0485(1985)015<1378:CAPOTN>2.0.CO;2

Huang, N. E. (1979). On surface drift currents in the ocean. Journal of Fluid Mechanics, 91(01), 191. https://doi.org/10.1017/ S0022112079000112

Huthnance, J. (1981). Waves and currents near the continental shelf edge. Progress in Oceanography, 10(4), 193-226. https://doi. org/10.1016/0079-6611(81)90004-5

Isern-Fontanet, J., Ballabrera-Poy, J., Turiel, A., \& García-Ladona, E. (2017). Remote sensing of ocean surface currents: A review of what is being observed and what is being assimilated. Nonlinear Processes in Geophysics, 24(4), 613-643. https://doi.org/10.5194/npg-24-613-2017

Jones, C. E., Dagestad, K.-F., Breivik, Ø., Holt, B., Röhrs, J., Christensen, K. H., et al. (2016). Measurement and modeling of oil slick transport. Journal of Geophysical Research: Oceans, 121, 7759-7775. https://doi.org/10.1002/2016JC012113 
Jones, S., Inall, M., Porter, M., Graham, J. A., \& Cottier, F. (2020). Storm-driven across-shelf oceanic flows into coastal waters. Ocean Science, 16(2), 389-403. https://doi.org/10.5194/os-16-389-2020

King, R. R., While, J., Martin, M. J., Lea, D. J., Lemieux-Dudon, B., Waters, J., \& O'Dea, E. (2018). Improving the initialisation of the Met Office operational shelf-seas model. Ocean Modelling, 130, 1-14. https://doi.org/10.1016/j.ocemod.2018.07.004

Kjellsson, J., \& Doos, K. (2012). Surface drifters and model trajectories in the Baltic Sea. Boreal Environment Research, 17, 447-459.

Komen, G. J., Cavaleri, L., Donelan, M., Hasselmann, K., Hasselmann, S., \& Janssen, P. A. E. M. (1994). Dynamics and modelling of ocean waves (p. 556). Cambridge University Press. https://doi.org/10.1017/CBO9780511628955

Kundu, P. K. (1976). Ekman veering observed near the ocean bottom. Journal of Physical Oceanography, 6, 238-242. https://doi.org/10.11 75/1520-0485(1976)006<0238:EVONTO>2.0.CO;2

Large, W. G., \& Yeager, S. G. (2009). The global climatology of an interannually varying air-sea flux data set. Climate Dynamics, 33(2-3), 341-364. https://doi.org/10.1007/s00382-008-0441-3

Lenain, L., \& Pizzo, N. (2020). The contribution of high-frequency wind-generated surface waves to the stokes drift. Journal of Physical Oceanography, 50(12), 3455-3465. https://doi.org/10.1175/JPO-D-20-0116.1

LeTraon, P. Y., Reppucci, A., Alvarez Fanjul, E., Aouf, L., Behrens, A., Belmonte, M., et al. (2019). From observation to information and users: The copernicus marine service perspective. Frontiers in Marine Science, 6. https://doi.org/10.3389/fmars.2019.00234

Lewis, H. W., Castillo Sanchez, J. M., Arnold, A., Fallmann, J., Saulter, A., Graham, J., et al. (2019). The UKC3 regional coupled environmental prediction system. Geoscientific Model Development, 12(6), 2357-2400. https://doi.org/10.5194/gmd-12-2357-2019

Lewis, H. W., Castillo Sanchez, J. M., Siddorn, J., King, R. R., Tonani, M., Saulter, A., et al. (2019). Can wave coupling improve operational regional ocean forecasts for the north-west European Shelf?. Ocean Science, 15(3), 669-690. https://doi.org/10.5194/os-15-669-2019

Li, J. -G. (2012). Propagation of ocean surface waves on a spherical multiple-cell grid. Journal of Computational Physics, 231(24), 82628277. https://doi.org/10.1016/j.jcp.2012.08.007

Liu, Y., \& Weisberg, R. H. (2011). Evaluation of trajectory modeling in different dynamic regions using normalized cumulative Lagrangian separation. Journal of Geophysical Research, 116, C09013. https://doi.org/10.1029/2010JC006837

Liubartseva, S., Coppini, G., Lecci, R., \& Clementi, E. (2018). Tracking plastics in the Mediterranean: 2D Lagrangian model. Marine Pollution Bulletin, 129(1), 151-162. https://doi.org/10.1016/j.marpolbul.2018.02.019

Lopez, G. (2017). Evaluation, analysis, and application of HF radar wave and current measurements, Phd dissertation. University of Plymouth.

Lopez, G., Bennis, A.-C., Barbin, Y., Sentchev, A., Benoit, L., \& Marié, L. (2020). Surface currents in the Alderney Race from high-frequency radar measurements and three-dimensional modelling. Philosophical Transactions of the Royal Society A: Mathematical, Physical \& Engineering Sciences, 378(2178), 20190494. https://doi.org/10.1098/rsta.2019.0494

Lopez, G., \& Conley, D. C. (2019). Comparison of HF radar fields of directional wave spectra against in situ measurements at multiple locations. Journal of Marine Science and Engineering, 7(8), 271. https://doi.org/10.3390/jmse7080271

Lumpkin, R., \& Pazos, M. (2009). Measuring surface currents with Surface Velocity Program drifters: The instrument, its data, and some recent results. In A. Griffa, A. D. J. Kirwan, A. J. Mariano, T. Ozgokmen, \& H. T. Rossby (Eds.), Lagrangian Analysis and Prediction of Coastal and Ocean dynamics (pp. 39-67). Cambridge: Cambridge University Press. https://doi.org/10.1017/CBO9780511535901.003

Madec, G., \& NEMO-team. (2016). NEMO ocean engine, Note du Pôle de modélisation (p. 357). Institut Pierre-Simon Laplace (IPSL).

Magnusson, L., \& Bidlot, J. (2016). Wind and wave forecasts during Storm Gertrude/Tor, in ECMWF Newsletter -147. Retrieved from https:// www.ecmwf.int/en/newsletter/147/news/wind-and-wave-forecasts-during-storm-gertrude-tor

Marié, L., Collard, F., Nouguier, F., Pineau-Guillou, L., Hauser, D., Boy, F., et al. (2020). Measuring ocean total surface current velocity with the KuROS and KaRADOC airborne near-nadir Doppler radars: A multi-scale analysis in preparation for the SKIM mission. Ocean Science, 16(6), 1399-1429. https://doi.org/10.5194/os-16-1399-2020

Masselink, G., Scott, T., Poate, T., Russell, P., Davidson, M., \& Conley, D. (2016). The extreme 2013/2014 winter storms: Hydrodynamic forcing and coastal response along the southwest coast of England. Earth Surface Processes and Landforms, 41(3), 378-391. https://doi. org/10.1002/esp.3836

McWilliams, J. C., Sullivan, P. P., \& Moeng, C. (1997). Langmuir turbulence in the ocean. Journal of Fluid Mechanics, 334, S0022112096004. https://doi.org/10.1017/S0022112096004375

Melville, W. K., Felizardo, C. F., \& Matusov, P. (2004). Wave slope and wave age effects in measurements of electromagnetic bias. Journal of Geophysical Research, 109(C7), C07. https://doi.org/10.1029/2002JC001708

Met Office (2016a), Storm Gertrude. (accessed 2020-08-18). Retrieved from https://www.metoffice.gov.uk/weather/warnings-and-advice/ uk-storm-centre/storm-gertrude

Met Office (2016b), Storm Henry. (accessed 2020-08-18). Retrieved from https://www.metoffice.gov.uk/weather/warnings-and-advice/ uk-storm-centre/storm-henry

Met Office (2016c), Storm Imogen. (accessed 2020-08-18). Retrieved from https://www.metoffice.gov.uk/weather/warnings-and-advice/ uk-storm-centre/storm-imogen

Niller, P. P., Davis, R. E., \& White, H. J. (1987). Water-following characteristics of a mixed layer drifter. Deep Sea Research Part A: Oceanographic Research Papers, 34(11), 1867-1881. https://doi.org/10.1016/0198-0149(87)90060-4

Paduan, J. D., \& Washburn, L. (2013). High-frequency radar observations of ocean surface currents. Annual Review of Marine Science, 5(1), 115-136. https://doi.org/10.1146/annurev-marine-121211-172315

Palmer, T., \& Saulter, A. (2016). Evaluating the effects of ocean current fields on a UK regional wave model. Techical Report, UK Met Office. Retrieved from https://www.metoffice.gov.uk/binaries/content/assets/mohippo/pdf/j/i/frtr_612_2016p.pdf

Parker, B. B. (2007). Tidal analysis and prediction (p. 378). Silver Spring, Maryland, USA. Tech. Rep. NOAA Special Publication NOS COOPS 3 .

Pazan, S. E., \& Niiler, P. P. (2001). Recovery of near-surface velocity from undrogued drifters. Journal of Atmospheric and Oceanic Technology, 18, 476-489. https://doi.org/10.1175/1520-0426(2001)018<0476:RONSVF >2.0.CO;2

Perlin, A., Moum, J. N., Klymak, J. M., Levine, M. D., Boyd, T., \& Kosro, P. M. (2007). Organization of stratification, turbulence, and veering in bottom Ekman layers. Journal of Geophysical Research, 112, C05S90. https://doi.org/10.1029/2004JC002641

Phillips, O. M. (1977). The dynamics of the upper ocean (2nd ed., p. 336). Cambridge.

Pierson, W. J., \& Moskowitz, L. (1964). A proposed spectral form for fully developed wind seas based on the similarity theory of S. A. Kitaigorodskii. Journal of Geophysical Research, 69(24), 5181-5190. https://doi.org/10.1029/JZ069i024p05181

Pizzo, N., Melville, W. K., \& Deike, L. (2019). Lagrangian transport by nonbreaking and breaking deep-water waves at the ocean surface. Journal of Physical Oceanography, 49(4), 983-992. https://doi.org/10.1175/JPO-D-18-0227.1 
Polton, J. A., Lewis, D. M., \& Belcher, S. E. (2005). The role of wave-induced coriolis-stokes forcing on the wind-driven mixed layer. Journal of Physical Oceanography, 35(4), 444-457. https://doi.org/10.1175/JPO2701.1

Rascle, N., Ardhuin, F., Queffeulou, P., \& Croizé-Fillon, D. (2008). A global wave parameter database for geophysical applications. Part 1: Wave-current-turbulence interaction parameters for the open ocean based on traditional parameterizations. Ocean Modelling, 25(3-4), 154-171. https://doi.org/10.1016/j.ocemod.2008.07.006

Reffray, G., Bourdalle-Badie, R., \& Calone, C. (2015). Modelling turbulent vertical mixing sensitivity using a 1-D version of NEMO. Geoscientific Model Development, 8(1), 69-86. https://doi.org/10.5194/gmd-8-69-2015

Rio, M.-H. (2012). Use of Altimeter and Wind Data to Detect the Anomalous Loss of SVP-Type Drifter's Drogue. Journal of Atmospheric and Oceanic Technology, 29(11), 1663-1674. https://doi.org/10.1175/JTECH-D-12-00008.1

Röhrs, J., Christensen, K. H., Hole, L. R., Broström, G., Drivdal, M., \& Sundby, S. (2012). Observation-based evaluation of surface wave effects on currents and trajectory forecasts. Ocean Dynamics, 62(10-12), 1519-1533. https://doi.org/10.1007/s10236-012-0576-y

Saulter, A. (2021). North West European Shelf Wave Analysis and Forecast - Quality Information Document, Copernicus Marine Environment Monitoring Service (CMEMS). accessed 2021-02-10. Retrieved from https://resources.marine.copernicus.eu/documents/QUID/ CMEMS-NWS-QUID-004-014.pdf

Saulter, A., Bunney, C., Li, J.-G., \& Palmer, T. (2017). Process and resolution impacts on UK coastal wave predictions from operational global-regional wave models. In 15th International Workshop on Wave Hindcasting and Forecasting \& 6th Coastal Hazard Symposium. accessed: 2020-08-20 (ISBN: 2020). Retrieved from http://www.waveworkshop.org/15thWaves/Papers/K1_WHF_SaulterEtAl_UKCoastalWave_20170913.pdf

Siddorn, J. R., \& Furner, R. (2013). An analytical stretching function that combines the best attributes of geopotential and terrain-following vertical coordinates. Ocean Modelling, 66, 1-13. https://doi.org/10.1016/j.ocemod.2013.02.001

Simpson, J. H. (1998). Tidal processes in shelf seas. In K. H. Brink, \& A. R. Robinson (Eds.), The Sea (Vol. 10, pp. 113-150). New York. John Wiley \& Sons.

Smith, S. D., \& Banke, E. G. (1975). Variation of the sea surface drag coefficient with wind speed. Quarterly Journal of the Royal Meteorological Society, 101(429), 665-673. https://doi.org/10.1002/qj.49710142920

Stanev, E. V., \& Ricker, M. (2020). Interactions between barotropic tides and mesoscale processes in deep ocean and shelf regions. Ocean Dynamics, 70(5), 713-728. https://doi.org/10.1007/s10236-020-01348-6

Staneva, J., Alari, V., Breivik, Ø., Bidlot, J.-R., \& Mogensen, K. (2017). Effects of wave-induced forcing on a circulation model of the North Sea. Ocean Dynamics, 67(1), 81-101. https://doi.org/10.1007/s10236-016-1009-0

Staneva, J., Ricker, M., Carrasco Alvarez, R., Breivik, Ø., \& Schrum, C. (2021). Effects of wave-induced processes in a coupled wave-ocean model on particle transport simulations. Water, 13(4), 415. https://doi.org/10.3390/w13040415

Staneva, J., Wahle, K., Günther, H., \& Stanev, E. (2016). Coupling of wave and circulation models in coastal-ocean predicting systems: A case study for the German Bight. Ocean Science, 12(3), 797-806. https://doi.org/10.5194/os-12-797-2016

Staneva, J., Wahle, K., Koch, W., Behrens, A., Fenoglio-Marc, L., \& Stanev, E. V. (2016). Coastal flooding: Impact of waves on storm surge during extremes \&ndash; A case study for the German Bight. Natural Hazards and Earth System Sciences, 16(11), 2373-2389. https:// doi.org/10.5194/nhess-16-2373-2016

Stigebrandt, A. (1985). A model for the seasonal pycnocline in rotating systems with application to the baltic proper. Journal of Physical Oceanography, 15, 1392-1404. https://doi.org/10.1175/1520-0485(1985)015<1392:AMFTSP > 2.0.CO;2

Stokes, G. (1847). On the theory of oscillatory waves. Transactions of the Cambridge Philosophical Society, 8, 441-455.

Sullivan, P. P., McWilliams, J. C., \& Melville, W. K. (2007). Surface gravity wave effects in the oceanic boundary layer: Large-eddy simulation with vortex force and stochastic breakers. Journal of Fluid Mechanics, 593, 405-452. https://doi.org/10.1017/S002211200700897X

Sutherland, G., Soontiens, N., Davidson, F., Smith, G. C., Bernier, N., Blanken, H., et al. (2020). Evaluating the leeway coefficient of ocean drifters using operational marine environmental prediction systems. Journal of Atmospheric and Oceanic Technology, 37(11), 1943-1954. https://doi.org/10.1175/JTECH-D-20-0013.1

Tamtare, T., Dumont, D., \& Chavanne, C. (2021). The Stokes drift in ocean surface drift prediction. Journal of Operational Oceanography, 1-13. https://doi.org/10.1080/1755876X.2021.1872229

Tang, C. L., Perrie, W., Jenkins, A. D., DeTracey, B. M., Hu, Y., Toulany, B., \& Smith, P. C. (2007). Observation and modeling of surface currents on the Grand Banks: A study of the wave effects on surface currents. Journal of Geophysical Research, 112, C10025. https://doi. org/10.1029/2006JC004028

Toffoli, A., \& Bitner-Gregersen, E. M. (2017). Types of ocean surface waves, wave classification. In Encyclopedia of maritime and offshore engineering (pp. 1-8). Chichester, UK. John Wiley \& Sons, Ltd. https://doi.org/10.1002/9781118476406.emoe077

Tolman, H. L. (2014). User manual and system documentation of WAVEWATCH III ${ }^{\circledast}$ version 4.18, Tech. rep (p. 316). NOAA/NWS/NCEP/ MMAB.

Tonani, M., Bruciaferri, D., Pequignet, A. C., King, R., Sykes, P., McConnell, N., \& Siddorn, J. (2021). North West European Shelf Ocean Analysis and Forecast - Quality Information Document, Copernicus Marine Environment Monitoring Service (CMEMS). accessed 2021 02 10. Retrieved from https://resources.marine.copernicus.eu/documents/QUID/CMEMS-NWS-QUID-004-013.pdf

Tonani, M., Sykes, P., King, R. R., McConnell, N., Péquignet, A. -C., O'Dea, E., et al. (2019). The impact of a new high-resolution ocean model on the Met Office North-West European Shelf forecasting system. Ocean Science, 15(4), 1133-1158. https://doi.org/10.5194/ os-15-1133-2019

Tuomi, L., Vähä-Piikkiö, O., Alenius, P., Björkqvist, J.-V., \& Kahma, K. K. (2018). Surface Stokes drift in the Baltic Sea based on modelled wave spectra. Ocean Dynamics, 68(1), 17-33. https://doi.org/10.1007/s10236-017-1115-7

Umlauf, L., \& Burchard, H. (2003). A generic length-scale equation for geophysical turbulence models. Journal of Marine Research, 61(2), 235-265. https://doi.org/10.1357/002224003322005087

Valiente, N. G., Masselink, G., Scott, T., Conley, D., \& McCarroll, R. J. (2019). Role of waves and tides on depth of closure and potential for headland bypassing. Marine Geology, 407, 60-75. https://doi.org/10.1016/j.margeo.2018.10.009

Waters, J., Lea, D. J., Martin, M. J., Mirouze, I., Weaver, A., \& While, J. (2015). Implementing a variational data assimilation system in an operational 1/4 degree global ocean model. Quarterly Journal of the Royal Meteorological Society, 141(687), 333-349. https://doi. $\operatorname{org} / 10.1002 /$ qj. 2388

Webb, A., \& Fox-Kemper, B. (2015). Impacts of wave spreading and multidirectional waves on estimating Stokes drift. Ocean Modelling, 96, 49-64. https://doi.org/10.1016/j.ocemod.2014.12.007

Wehde, H., Schuckmann, K. V., Pouliquen, S., Grouazel, A., Bartolome, T., Tintore, J., et al. (2021). North West European Shelf In-Situ Observations. https://doi.org/10.13155/43494 
Wei, X., Brown, J. M., Williams, J., Thorne, P. D., Williams, M. E., \& Amoudry, L. O. (2019). Impact of storm propagation speed on coastal flood hazard induced by offshore storms in the North Sea. Ocean Modelling, 143, 101472. https://doi.org/10.1016/j.ocemod.2019.101472

Wu, L., Staneva, J., Breivik, Ø., Rutgersson, A., Nurser, A. G., Clementi, E., \& Madec, G. (2019). Wave effects on coastal upwelling and water level. Ocean Modelling, 140, 101405. https://doi.org/10.1016/j.ocemod.2019.101405

Zodiatis, G., De Dominicis, M., Perivoliotis, L., Radhakrishnan, H., Georgoudis, E., Sotillo, M., et al. (2016). the mediterranean decision support system for marine safety dedicated to oil slicks predictions. Deep-Sea Research Part II Topical Studies in Oceanography, 133. https://doi.org/10.1016/j.dsr2.2016.07.014 